CrossMark

Cite as

Nano-Micro Lett.

(2019) 11:8

Received: 5 November 2018

Accepted: 24 December 2018

Published online: 19 January 2019

(C) The Author(s) 2019

\section{Flexible, Porous, and Metal-Heteroatom-Doped Carbon Nanofibers as Efficient ORR Electrocatalysts for Zn-Air Battery}

\author{
Qijian Niu ${ }^{1,2}$, Binling Chen ${ }^{3}$, Junxia Guo ${ }^{1,2}$, Jun $\mathrm{Nie}^{1,2}$, Xindong Guo ${ }^{1,2}$, \\ Guiping $\mathrm{Ma}^{1,2} \otimes$ \\ Qijian Niu and Binling Chen have contributed equally to this work. \\ $\bowtie$ Binling Chen, B.Chen@exeter.ac.uk; Guiping Ma, magp@mail.buct.edu.cn \\ 1 Key Laboratory of carbon Fiber and Functional Polymers, Ministry of Education, Beijing University \\ of Chemical Technology, Beijing 100029, People's Republic of China \\ 2 State Key Laboratory of Chemical Resource Engineering, Beijing University of Chemical Technology, \\ Beijing 100029, People's Republic of China \\ 3 College of Engineering, Mathematics and Physical Sciences, University of Exeter, Exeter EX4 4QF, UK
}

\title{
HIGHLIGHTS
}

- Doping and porosity generation were completed simultaneously.

- Metal-heteroatom-doped carbon nanofibers are flexible, porous, and well dispersed.

- Results include excellent oxygen reduction reaction and enhanced $\mathrm{Zn}$-air battery performance.

\begin{abstract}
Developing an efficient and durable oxygen reduction electrocatalyst is critical for clean-energy technology, such as fuel cells and metal-air batteries. In this study, we developed a facile strategy for the preparation of flexible, porous, and well-dispersed metal-heteroatom-doped carbon nanofibers by direct carbonization of electrospun Zn/Co-ZIFs/PAN nanofibers (Zn/Co-ZIFs/PAN). The obtained Zn/ $\mathrm{Co}$ and $\mathrm{N}$ co-doped porous carbon nanofibers carbonized at $800{ }^{\circ} \mathrm{C}(\mathrm{Zn} / \mathrm{Co}-\mathrm{N} @$ PCNFs-800) presented a good flexibility, a continuous porous structure, and a superior oxygen reduction reaction (ORR) catalytic activity to that of commercial $20 \mathrm{wt} \%$ $\mathrm{Pt} / \mathrm{C}$, in terms of its onset potential $(0.98 \mathrm{~V}$ vs. RHE), half-wave potential $(0.89 \mathrm{~V}$ vs. RHE), and limiting current density $\left(-5.26 \mathrm{~mA} \mathrm{~cm}^{-2}\right)$. In addition, we tested the suitability and durability of Zn/Co-N@PCNFs-800 as the oxygen cathode for a rechargeable $\mathrm{Zn}$-air battery. The prepared $\mathrm{Zn}$-air batteries exhibited a higher power density $\left(83.5 \mathrm{~mW} \mathrm{~cm}^{-2}\right)$, a higher specific capacity $\left(640.3 \mathrm{mAh} \mathrm{g}^{-1}\right)$, an excellent reversibility, and a better cycling life than the commercial $20 \mathrm{wt} \% \mathrm{Pt} / \mathrm{C}+\mathrm{RuO}_{2}$ cata-

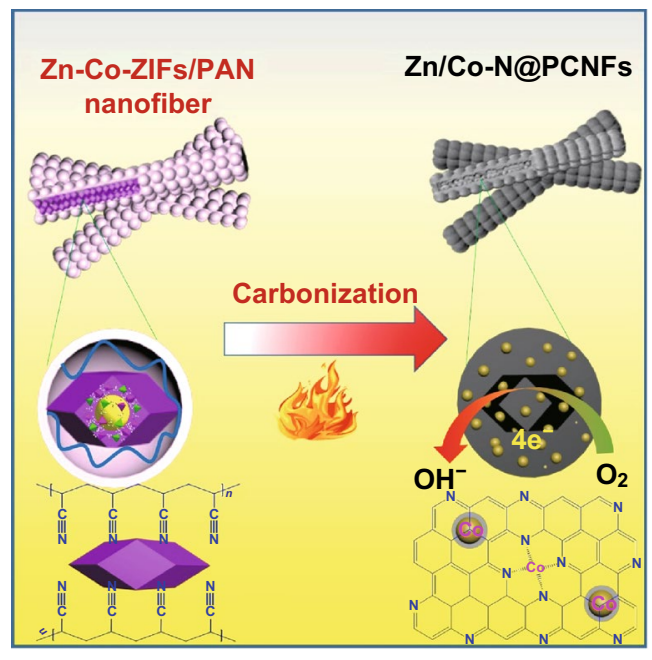
lysts. This design strategy of flexible porous non-precious metal-doped ORR electrocatalysts obtained from electrospun ZIFs/polymer nanofibers could be extended to fabricate other novel, stable, and easy-to-use multi-functional electrocatalysts for clean-energy technology.
\end{abstract}

KEYWORDS Electrospinning; Zn/Co-ZIFs; Carbon nanofibers; Flexible porous structure; ORR; Zn-air battery 


\section{Introduction}

New energy technology has become an optimal solution for the energy crisis and environmental pollution caused by the rapid depletion of fossil resources [1,2]. Recently, sustainable energy conversion and storage systems, such as supercapacitors, fuel cells, and batteries, have been developed rapidly. Among these various new energy devices, fuel cells and metal-air batteries have received increasing attention because of their low contribution to pollution. However, the oxygen reduction reaction (ORR), one of the key reactions of fuel cells and metal-air batteries, has sluggish intrinsic electrode kinetics, hampering the practical application of fuel cells and metal-air batteries [3]. Up to now, Pt-based materials are known as the best catalytic materials for ORR. However, these materials suffer from the prohibitive cost, severe scarcity, serious intermediate tolerance, and poor stability [4]. As an alternative, non-precious metaldoped carbon-based materials with various nanostructures, such as porous/hollow carbon nanoparticles [5-7], porous/ core-shell carbon nanofibers [8-10], porous/sandwich-type graphene nanosheets [11-13], and porous graphene aerogels [14, 15], have emerged and attracted great attention. Porous carbon materials, containing catalytic active metal nanoparticles for effective catalysis, have been regarded as crucial supporting materials, owing to their high specific surface area, highly porous structure, and excellent electrical conductivity.

Metal-organic frameworks (MOFs), constructed by bridging metal ions and organic functional ligands into threedimensional (3D) ordered crystal frameworks with rich micropores and high surface areas, provide a good platform for designing metal-heteroatom-doped carbon catalysts [16, 17]. The first MOF used as a template for porous carbon synthesis was reported by $\mathrm{Xu}$ et al. [18]. Among the different types of MOFs, zeolitic imidazole frameworks (ZIFs), a subclass of MOFs, are the most-studied candidates because of their high content of nitrogen and metal ions [19]. Moreover, such complex units consisting of nitrogen and metal ions $\left(\mathrm{MN}_{4}\right)$ are easy to form active sites for ORR. Thus, N-rich ZIFs (e.g., ZIF-8, ZIF-67, bimetallic Zn/Co-ZIFs) were used as self-sacrificing templates and precursors to construct electrocatalysts with high surface areas, uniform $\mathrm{N}$ doping, and $\mathrm{Co}-\mathrm{N}_{x}$ active sites by the high-temperature carbonization [20]. However, there remain some problems associated with the obtained ZIF-derived electrocatalysts, such as poor electrical conductivity, aggregation of loaded metal nanoparticles, and poor mechanical stability, which may affect their practical applications.

Recently, combining ZIFs with low-dimensional materials has gotten an increasing amount of attention. Tellurium nanowire-directed templating synthesis of ZIF-8 nanofibers has been demonstrated by Wang Zhang et al. [21]. After carbonization, the as-obtained ZIF-8 nanofibers can be easily converted into highly porous carbon nanofibers with complex network structures, hierarchical pores, and high surface areas, which are beneficial to the improvement of electrochemical properties. Ahn et al. [22, 23] reported a similar synthesis of one-dimensional (1D) hierarchically porous $\mathrm{N}$ - and Co-doped carbon nanotubes for efficient ORR by combining a 1D tellurium nanotube as the main template for the carbon nanotube backbone, with an anchored $\mathrm{Zn} / \mathrm{Co}-$ ZIF as a sub-template for the carbon framework. The porous carbon derived from the bimetallic composites of ZIF-8 and ZIF-67, with a proper ratio, generates synergistic effects, such as a high degree of graphitic carbon, a formation of $\mathrm{Co}-\mathrm{N}_{x}$ active sites, and a high surface area. To improve the inter-particle conductivity of the electrocatalysts, multiwall carbon nanotubes (MWCTs) were used in ZIF synthesis, which interconnect the nanoparticles and provide electron conducting highways. Zhang et al. [24] introduced MWCNTs to increase the electronic conductivity and mass transport of ORR catalysts derived from bimetallic Zn/Fe-ZIFs. $\mathrm{ZnO}$ nanorods and nanowires were also used as facile selfsacrifice templates to fabricate hierarchically porous carbon nanotubes from core-shell ZnO@ZIF-8 nanorods and $\mathrm{ZnO} @ \mathrm{Zn} / \mathrm{Co}-\mathrm{ZIFs}$ nanowires [25, 26]. The in situ reduction and evaporation of $\mathrm{ZnO}$ effectively resolved the aggregation issue during carbonization and therefore formed hierarchical pores without using any extra template. 1D carbon nanofiber materials have been paid extensive attention due to their excellent conductivity and flexibility, which are beneficial to improving their catalytic performance and designing flexible electronic devices [27, 28]. Moreover, carbon nanofibers not only solve the above-mentioned waste of inorganic templates but also provide longer electron transport channels. Electrospinning is a simple and efficient method for the preparation of nanofibers [29, 30]. Direct carbonization of electrospun precursor nanofibers is a fast and efficient method for preparing carbon nanofibers [31,32]. Carbon nanofibers obtained via electrospinning followed by a subsequent 
carbonization have several advantages: (1) high electrical conductivity through the connection between the nanofibers, (2) fast mass transmission from the network structure and high surface area, and (3) cost effectiveness from the simple preparation procedure [33]. In our previous work, $\mathrm{Zn} / \mathrm{Co}-\mathrm{ZIFs} / \mathrm{PAN}$ core-shell nanofibers were well-designed and prepared through $\mathrm{Zn} / \mathrm{Co}$-ZIFs grown in situ on the surface of electrospun nanofibers [34]. The results showed that electrochemical performance was improved. However, the electrochemical performance was still worse than that of the commercial catalyst, which may be due to its small surface area. Recently, Liu et al. [35] developed a novel N, Cocontained MOF-based hierarchical carbon nanofiber as an ORR catalyst, which was synthesized by incorporating $\mathrm{Zn} /$ Co-ZIFs with electrospun $\mathrm{Co}^{2+} / \mathrm{PAN}$ nanofibers, followed by carbonization and acid-leaching treatment. However, the size of the prepared ZIF nanocrystals is ultra-small in their study, and additional metal ions $\left(\mathrm{Co}^{2+}\right)$ were required for the electrospinning process. Based on these studies, we investigated combining electrospun PAN nanofibers with just as-prepared $\mathrm{Zn} / \mathrm{Co}-\mathrm{ZIFs}$ in different contents, as a precursor for flexible, porous, and well-dispersed metal-heteroatom-doped carbon nanofiber catalysts.

Herein, we report a facile approach to prepare well-dispersed metal $(\mathrm{Zn} / \mathrm{Co})$ and heteroatom $(\mathrm{N})$ co-doped porous carbon nanofibers ( $\mathrm{Zn} / \mathrm{Co}-\mathrm{N} @ \mathrm{PCNFs})$ film based on electrospun $\mathrm{Zn} / \mathrm{Co}-\mathrm{ZIFs} / \mathrm{PAN}$ nanofibers. During the process, $\mathrm{Zn} / \mathrm{Co}$-ZIF nanocrystals with a larger size $(\sim 900 \mathrm{~nm})$ and different contents were loaded onto electrospun PAN nanofiber without any additional metal ions. Such a facile method not only can yield a hierarchical porous structure but can also achieve a good distribution of metal active sites in the porous carbon nanofibers, which is important for ORR. Zn/Co-N@PCNFs-800 (carbonization temperature is $800{ }^{\circ} \mathrm{C}$ ) exhibited an excellent ORR performance. In addition, the suitability and durability of $\mathrm{Zn} / \mathrm{Co}-\mathrm{N} @$ PCNFs-800 were tested as the oxygen cathode for primary and rechargeable $\mathrm{Zn}$-air batteries, showing relatively good electrochemical properties.

\section{Experimental Section}

\subsection{Materials}

Polyacrylonitrile (PAN, $M_{\mathrm{w}}=150,000 \mathrm{~g} \mathrm{~mol}^{-1}$ ), zinc nitrate hexahydrate $\left(\mathrm{Zn}\left(\mathrm{NO}_{3}\right)_{2} \cdot 6 \mathrm{H}_{2} \mathrm{O}\right)$, cobalt nitrate hexahydrate $\left(\mathrm{Co}\left(\mathrm{NO}_{3}\right)_{2} \cdot 6 \mathrm{H}_{2} \mathrm{O}\right)$, 2-methylimidazole $\left(\mathrm{C}_{4} \mathrm{H}_{6} \mathrm{~N}_{2}, \mathrm{MIM}\right)$, methanol $(\mathrm{MeOH})$, ethanol (EtOH, $\geq 99.7 \%)$, potassium hydroxide (KOH, 98\%), and $N, N$-dimethylformamide (DMF) were all purchased from Aladdin Chemical Reagent Co. Nafion solution (5 wt \%) was purchased from DuPont Co. Common commercial $20 \mathrm{wt} \% \mathrm{Pt} / \mathrm{C}$ catalyst and $\mathrm{RuO}_{2}$ were bought from Johnson Matthey Co. All chemicals were of analytical grade and used without further purification.

\subsection{Preparation of the Samples}

\subsubsection{Preparation of Zn/Co-ZIF Nanocrystals}

The preparation of $\mathrm{Zn} / \mathrm{Co}$-ZIF nanocrystals was based on a previous procedure with modifications [36]. Typically, $5.0 \mathrm{mmol} \mathrm{Zn}\left(\mathrm{NO}_{3}\right)_{2} \cdot 6 \mathrm{H}_{2} \mathrm{O}$ and $10.0 \mathrm{mmol} \mathrm{Co}\left(\mathrm{NO}_{3}\right)_{2} \cdot 6 \mathrm{H}_{2} \mathrm{O}$ were dissolved into $150 \mathrm{~mL}$ methanol to form a clear solution. The molar ratio of $\mathrm{Zn}^{2+} / \mathrm{Co}^{2+}$ was set to $1 / 2$. A mixture of $60 \mathrm{mmol}$ 2-methylimidazole with $50 \mathrm{~mL}$ methanol was added to the above solution with $12 \mathrm{~h}$ incubation at room temperature. The product was separated by centrifugation and then washed thoroughly with methanol three times, and finally dried overnight at $60^{\circ} \mathrm{C}$ under a vacuum oven.

\subsubsection{Preparation of the Zn/Co-ZIFs/PAN Precursor Nanofibers}

The Zn/Co-ZIFs/PAN precursor nanofibers were prepared by electrospinning [37]. In a typical experiment, $0.5 \mathrm{~g}$ PAN powder was dissolved into 4.5 g DMF solvent [38]. The blended solution was continuously stirred for $6 \mathrm{~h}$ at $40{ }^{\circ} \mathrm{C}$. Then, $1.0 \mathrm{~g}$ $\mathrm{Zn} / \mathrm{Co}-\mathrm{ZIF}$ nanoparticles were added into above solution and stirred for another $6 \mathrm{~h}$ at $40{ }^{\circ} \mathrm{C}$. Afterward, the electrospinning process was carried out with a high voltage of $20 \mathrm{kV}$ and an extrusion rate of $0.6 \mathrm{~mL} \mathrm{~h}^{-1}$. The obtained nanofibers were collected on aluminum foil $\left(\sim 15 \times 15 \mathrm{~cm}^{2}\right)$. The collect distance between the nozzle and the aluminum foil was $15 \mathrm{~cm}$. The Zn/Co-ZIFs/PAN nanofiber film was easily peeled off 
from the collector and put into a vacuum oven overnight at a temperature of $80{ }^{\circ} \mathrm{C}$ to remove the residual solvents.

\subsubsection{Preparation of the $\mathrm{Zn} / \mathrm{Co}-\mathrm{N} @ \mathrm{PCNF}$ Electrocatalysts from Zn/Co-ZIFs/PAN Nanofibers}

The obtained $\mathrm{Zn} / \mathrm{Co}-\mathrm{ZIFs} / \mathrm{PAN}$ nanofiber film was pre-oxidized at $280{ }^{\circ} \mathrm{C}$ for $2 \mathrm{~h}$ at a heating rate of $2{ }^{\circ} \mathrm{C} \mathrm{min}{ }^{-1}$ under air atmosphere. The obtained pre-oxidized nanofiber film was then directly carbonized at the target temperatures $(500$, $600,700,800,900$, and $1000{ }^{\circ} \mathrm{C}$ ) for $2 \mathrm{~h}$ at a heating rate of $5{ }^{\circ} \mathrm{C} \min ^{-1}$ in $\mathrm{N}_{2}$ atmosphere and then naturally cooled to room temperature to obtain the flexible, porous, and welldispersed metal-heteroatom-doped carbon nanofibers. (The samples were named as Zn/Co-N@PCNFs-T, where T is the target carbonization temperature.)

\subsection{Physical Characterizations}

The microstructure and surface morphology of the obtained samples were observed by scanning electron microscopy (SEM, S-4700, Hitachi, Japan). The internal structure and graphitic structure were investigated by transmission electron microscopy (TEM, Tecnai G2 T20, FEI, USA) and high-resolution transmission electron microscopy (HR-TEM, JEM 3010, JEOL, Japan). Scanning transmission electron microscopy (STEM) and color mapping were employed to distinguish the elemental dispersion in these samples by HRTEM. The thermal decomposition behavior of the precursor nanofibers was determined by thermal gravimetric analysis (TGA, Q500, TA Instruments, USA). Fourier transform infrared (FT-IR) spectra of the samples were measured by spectrometer (Nicolet-is5 IR, Thermo Fisher Scientific, USA). The crystal structure of the samples was evaluated on a powder X-ray diffraction (XRD, D8 Advance, Bruker, Germany) system with $\mathrm{Cu}-\mathrm{K} \alpha$ radiation. Raman spectra analysis was conducted on a Raman spectrometer (Invia Reflex, Renishaw, British) at $514 \mathrm{~nm}$. X-ray photoelectron spectroscopy (XPS, Thermal Scientific K-Alpha XPS spectrometer) was employed to analyze the chemical composition of these samples. Nitrogen absorption/desorption isotherms were obtained on a Quantachrome Autosorb-iQ gas sorptometer via the conventional volumetric technique, and the corresponding surface areas were determined by using the Brunauer-Emmett-Teller (BET) method.

\subsection{Electrochemical Measurements}

All electrochemical measurements were performed in a three-electrode system on an electrochemical workstation (CHI 760E, Shanghai Chenhua, China) in 0.1 M KOH electrolyte. A glassy carbon (GC) rotating disk electrode (RDE, ALS, Japan) of $4.0 \mathrm{~mm}$ in diameter was used as a working electrode. Before use, the working electrode was polished carefully with $50 \mathrm{~nm} \mathrm{Al}_{2} \mathrm{O}_{3}$ powders to obtain a mirror-like surface and then washed with deionized water and ethanol and allowed to dry. A platinum wire and $\mathrm{Ag} / \mathrm{AgCl}(3.0 \mathrm{M}$ $\mathrm{KCl}$ ) electrode were used as the counter and reference electrodes, respectively. The electrochemical measurements were carried out in a $0.1 \mathrm{~mol} \mathrm{~L}^{-1} \mathrm{KOH}$ aqueous electrolyte at the temperature of $298 \mathrm{~K}$. To prepare the working electrode, $5.0 \mathrm{mg}$ of the catalyst was dispersed in a solution consisting of $1.0 \mathrm{~mL}$ of absolute ethanol and $100 \mu \mathrm{L}$ of $5 \mathrm{wt} \%$ Nafion, and then sonicated for $1 \mathrm{~h}$ to form a well-dispersed black catalyst ink. For the catalyst ink, $5.0 \mu \mathrm{L}$ was drop-cast onto the glassy carbon surface $\left(\sim 0.18 \mathrm{mg} \mathrm{cm}^{-2}\right.$ loading $)$ and dried at room temperature for electrochemical testing. The working electrodes were scanned for about 50 cycles until the signals were stabilized, and then, the data were collected. Before testing, a continuous $\mathrm{N}_{2} / \mathrm{O}_{2}$ flow was bubbled into the electrolyte for $30 \mathrm{~min}$. The cyclic voltammetry (CV) experiments were cycled in $0.1 \mathrm{M} \mathrm{N}_{2}$ - and $\mathrm{O}_{2}$-saturated $\mathrm{KOH}$ electrolyte solutions with a sweep rate of $50 \mathrm{mV} \mathrm{s}^{-1}$. The RDE tests were measured in $0.1 \mathrm{M} \mathrm{O}_{2}$-saturated $\mathrm{KOH}$ electrolyte solutions with a sweep rate of $10 \mathrm{mV} \mathrm{s}^{-1}$ and different speed rates (400-2500 rpm). For comparison, $20 \mathrm{wt} \% \mathrm{Pt} / \mathrm{C}$ was used in the same electrochemical tests.

For the ORR on an RDE, the electron transfer numbers can be calculated with Koutecky-Levich equations (Eqs. 1-3):

$$
\begin{aligned}
& \frac{1}{j}=\frac{1}{j_{\mathrm{L}}}+\frac{1}{j_{\mathrm{K}}}=\frac{1}{B \omega^{1 / 2}}+\frac{1}{j_{\mathrm{K}}} \\
& j_{k}=n F k C_{0} \\
& B=0.2 n F C_{0}\left(D_{0}\right)^{2 / 3} V^{-1 / 6}
\end{aligned}
$$

where $j$ is the measured current density; $j_{\mathrm{K}}$ and $j_{\mathrm{L}}$ are the kinetic and diffusion-limiting current densities, respectively; $\omega$ is rotation speed (rpm); $n$ represents the electron transfer number in the oxygen reduction reaction; $F$ is the Faraday constant $\left(F=96,485 \mathrm{C} \mathrm{mol}^{-1}\right) ; C_{0}$ is the bulk concentration 
of $\mathrm{O}_{2}\left(1.2 \times 10^{-6} \mathrm{~mol} \mathrm{~cm}^{-3}\right) ; D_{0}$ is the diffusion coefficient of $\mathrm{O}_{2}$ in $0.1-\mathrm{M} \mathrm{KOH}$ electrolyte $\left(1.9 \times 10^{-5} \mathrm{~cm}^{2} \mathrm{~s}^{-1}\right)$; $V$ is the kinematic viscosity for electrolyte $\left(0.01 \mathrm{~cm}^{-2} \mathrm{~s}^{-1}\right)$; and $k$ is the electron transfer rate constant. All potentials in this study were converted to the RHE reference scale using $E$ (vs. $\mathrm{RHE})=E($ vs. $\mathrm{Ag} / \mathrm{AgCl})+0.21 \mathrm{~V}+0.0591 \times \mathrm{pH}$.

$\mathrm{Zn}$-air battery assembly and test: the rechargeable $\mathrm{Zn}$-air battery performance was tested using a homemade $\mathrm{Zn}$-air battery. To assemble the $\mathrm{Zn}$-air battery, a polished zinc plate ( $0.3 \mathrm{~mm}$ of thickness) was used as the anode; an air electrode coated by $100 \mu \mathrm{L}$ catalyst ink of Zn/Co-N@PCNFs-800 or a mixture of $20 \mathrm{wt} \% \mathrm{Pt} / \mathrm{C}+\mathrm{RuO}_{2}(1: 1$ in a mass ratio) onto carbon paper (electrode area: $0.8 \mathrm{~cm}$ in diameter; catalyst loading: $1.2 \mathrm{mg} \mathrm{cm}^{-2}$ ), dried naturally to form a uniform catalyst layer, was used as the cathode; and 6.0 M KOH solution served as the electrolyte. The potential-current polarization curves for the batteries were recorded on a $\mathrm{CHI} 760 \mathrm{e}$ workstation. The discharge/charge performance and stability for the batteries were analyzed by a Lanhe-CT2001A testing system at room temperature [39].

\section{Results and Discussion}

The preparation process of $\mathrm{Zn} / \mathrm{Co}-\mathrm{N} @ \mathrm{PCNF}$ s obtained from electrospun $\mathrm{Zn} / \mathrm{Co}-\mathrm{ZIFs} / \mathrm{PAN}$ nanofibers is shown in Fig. 1. First, Zn/Co-ZIFs/PAN nanofibers were fabricated via an electrospinning method. Next, the as-obtained precursor nanofibers were carbonized directly at high temperature. The obtained carbon nanofibers were directly used as ORR electrocatalysts. Figure 1b, c shows the simulated cross section diagram and simulated molecular structure diagram, respectively, in different experimental stages. In the electrospinning process (I), the polymer chain of PAN wound around

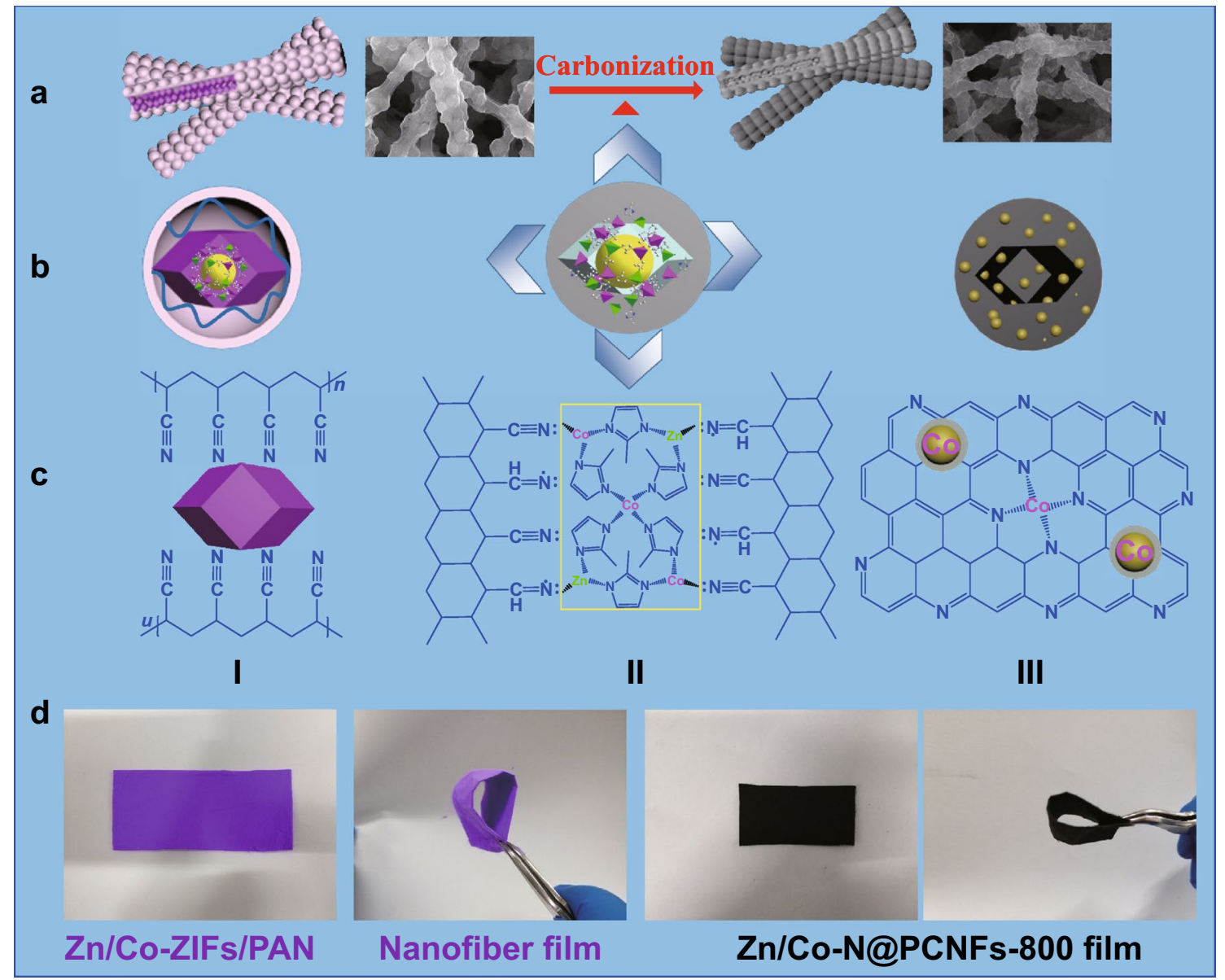

Fig. 1 Schematic illustration for the preparation of Zn/Co-N@PCNFs from electrospun Zn/Co-ZIFs/PAN nanofibers. a The micro-morphologies of the nanofibers before and after carbonization. b The simulated cross section diagram. $\mathbf{c}$ The simulated molecular structure diagram. d The digital photographs of the nanofiber film before and after carbonization 
the Zn/Co-ZIF nanocrystals, forming an organic-inorganic compound system. During the carbonization process (II), the polymer chain of PAN formed a trapezoidal structure through the complex cyclic dehydrogenation reaction [40]. The skeleton of ZIF nanocrystals began to collapse in the carbonization process. During this process, the nitrogen atoms from the 2-methylimidazole and PAN polymer reconnected to the metal ions, making a uniform formation of active sites (metal nanoparticles, $\mathrm{N}_{x}-\mathrm{C}$, and metal- $\mathrm{N}_{x}-\mathrm{C}$ ) in the carbon nanofibers [41]. After carbonization (III), the $\mathrm{N}$-doped graphite carbon layer was formed, which is also mainly embedded with cobalt nanoparticles and complex $\mathrm{Co}-\mathrm{N}_{x}-\mathrm{C}$ catalytic activity sites. In addition, empty cavities formed from the position where the original $\mathrm{Zn} / \mathrm{Co}-\mathrm{ZIF}$ nanocrystals occupied before. This phenomenon suggests that the $\mathrm{Zn} / \mathrm{Co}$-ZIF nanocrystals not only serve as a doping agent but also serve as a pore-forming template. These continuous cavities form a porous structure, facilitating mass transfer during the catalytic process. Moreover, the large amount of $\mathrm{Zn}$ evaporation also plays a role in pore-forming, which enlarges the surface area and prevents the aggregation of cobalt nanoparticles. The digital photographs of the samples are shown in Fig. 1d, showing that the color of the nanofiber film changed from purple to black after carbonization, which indicates that the organic-inorganic composite system was converted into inorganic carbon nanofiber materials. Interestingly, Zn/Co-N@PCNFs-800 film still maintains flexible properties and a fibrous structure, which can facilitate its use as a self-supporting flexible device [42].

The morphologies and structural features of the synthesized Zn/Co-ZIFs/PAN nanofibers and Zn/Co-N@ PCNFs-800 were observed through SEM and TEM (Figs. 2 and S1). As shown in Fig. 2a, Zn/Co-ZIFs/PAN nanofibers have a raised rough surface. As the content of $\mathrm{Zn} / \mathrm{Co}-$ ZIF nanoparticles increases, the roughness of the nanofiber surface increases (Fig. S1). However, the raised rough surface became folded after carbonization (Figs. 2b, S2, S3). In addition, the diameter of the nanofiber becomes smaller because of the volume contraction during the carbonization process. The TEM image (Fig. 2c) shows that the $\mathrm{Zn} / \mathrm{Co}-$ ZIFs were successfully embedded into the PAN nanofibers. After the carbonization process, the porous empty cavities from the position of the original $\mathrm{Zn} / \mathrm{Co}-\mathrm{ZIFs}$ can be found in the carbon nanofibers, which is due to the collapse and volatilization of Zn/Co-ZIFs during the carbonization (Figs. 2d, S4). STEM elemental mapping was used to characterize the elemental distribution and change. As shown in Fig. 2e, the elements of $\mathrm{Zn}$, Co, and $\mathrm{N}$ of $\mathrm{Zn} / \mathrm{Co}-\mathrm{ZIFs} / \mathrm{PAN}$ are mainly concentrated in the $\mathrm{Zn} / \mathrm{Co}-\mathrm{ZIFs}$. However, these elements are distributed on the nanofiber matrix uniformly after carbonization (Fig. 2f), which proves that Zn/Co-ZIFs play the roles of both self-sacrificing templates and doping agents.
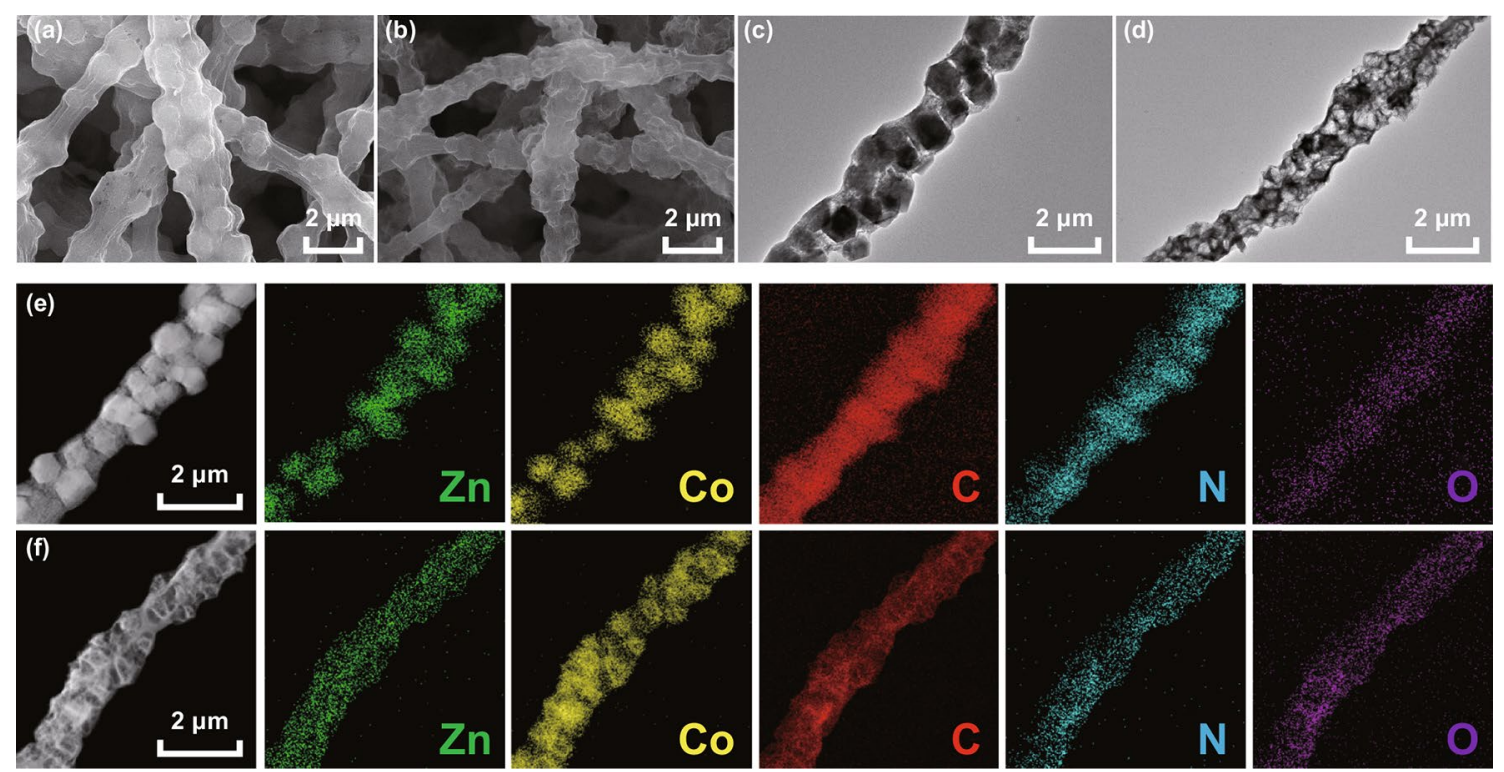

Fig. 2 SEM images of the a Zn/Co-ZIFs/PAN nanofibers and b Zn/Co-N@PCNFs-800. TEM images of a single nanofiber $\mathbf{c} \mathrm{Zn/Co-ZIFs/PAN}$ nanofiber and $\mathbf{d} \mathrm{Zn} / \mathrm{Co}-\mathrm{N} @$ PCNFs-800. HR-TEM images and STEM elemental mappings of e a single Zn/Co-ZIFs/PAN nanofiber and $\mathbf{f}$ a single Zn/Co-N@PCNFs-800 
The carbonization process plays an important role in the performance of carbon-based ORR catalysts. Therefore, TG and DTG were used to monitor the carbonization behavior of $\mathrm{Zn} / \mathrm{Co}-\mathrm{ZIFs} / \mathrm{PAN}$ nanofibers in $\mathrm{N}_{2}$ atmosphere (Fig. 3a). As we can see, the typical PAN degradation peak appeared at $\sim 300^{\circ} \mathrm{C}$, which is likely associated with complex chemical reactions (dehydrogenation, cyclization, and cross-linking) during the stabilization process. The peak at $\sim 550{ }^{\circ} \mathrm{C}$ for Zn/Co-ZIFs decomposition becomes broader [34], indicating that the $\mathrm{Zn} / \mathrm{Co}$-ZIF nanocrystals were embedded in the body of the nanofibers, which is consistent with the TEM images (Fig. 2c). The FT-IR spectra (Fig. 3b) were used to study the change in the functional groups during the carbonization process. The prominent organic functional group peaks gradually disappeared with increase in carbonization temperature, confirming that the organic-inorganic complex was converted into inorganic carbon materials. XRD patterns of the prepared samples are shown in Fig. 3c. The
XRD patterns of the $\mathrm{Zn} / \mathrm{Co}-\mathrm{ZIFs} / \mathrm{PAN}$ nanofibers are in good agreement with the simulated ZIFs, further suggesting that the PAN polymer matrix does not affect the ZIF crystal structure. The XRD patterns of different carbonized samples have four main peaks at $26^{\circ}, 44.5^{\circ}, 52^{\circ}$, and $76^{\circ}$, corresponding to the C (002), Co (111), Co (200), and Co (220) diffractions, respectively. Interestingly, a peak center at $41.3^{\circ}$ for $\mathrm{Co}_{2} \mathrm{C}(002)$ appears at the higher carbonization sample temperature of $1000{ }^{\circ} \mathrm{C}$. It is well known that the carbon graphitization and metal doping in the catalysts could enhance electronic conductivity and increase the number of active sites in electrocatalysts. Raman spectra were used to characterize the graphitization degree of the samples. All the Raman spectra display two prominent D-band and G-band peaks. Generally, the intensity ratio of the D-band to G-band $\left(I_{\mathrm{D}} / I_{\mathrm{G}}\right)$ is used to estimate the disorder degree of the carbon material. As shown in Fig. 3d, the intensity ratios of $I_{\mathrm{D}} / I_{\mathrm{G}}$ vary from 1.30 to 1.01 with the increase of carbonization (a)

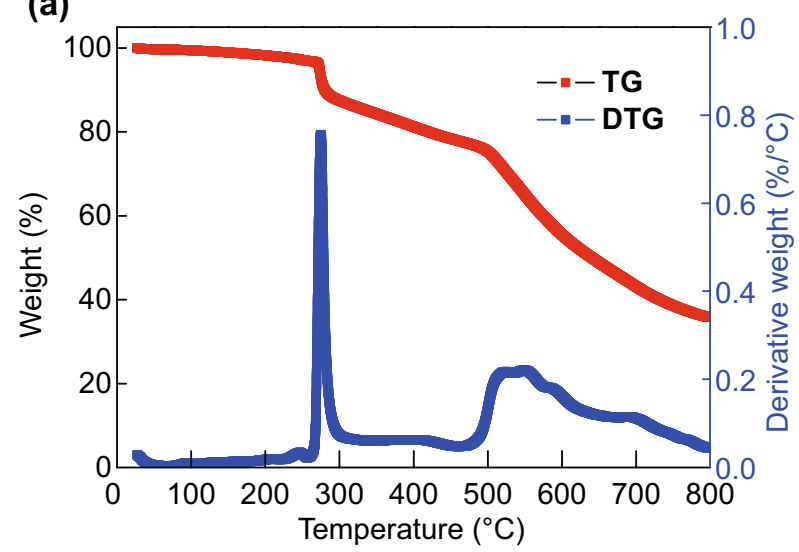

(c)

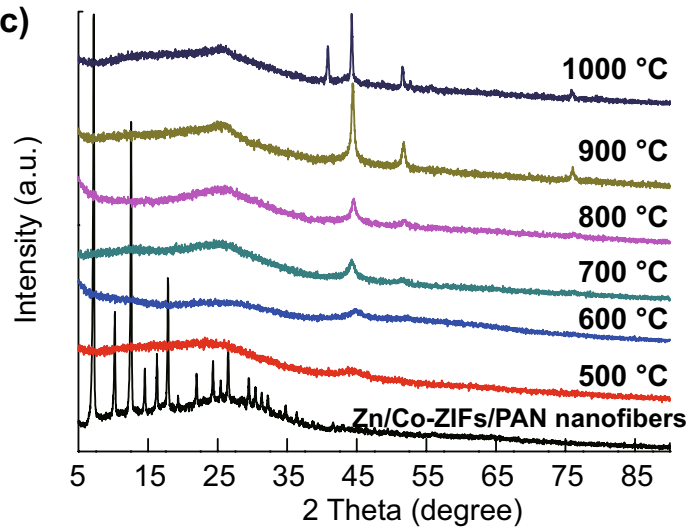

(b)

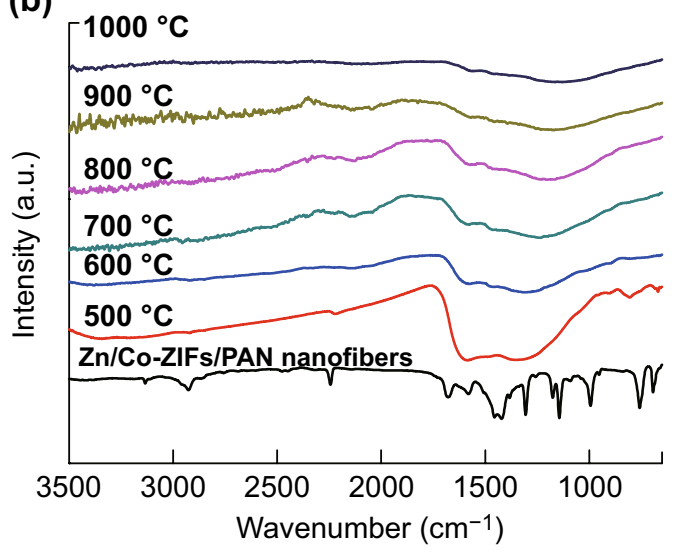

(d)

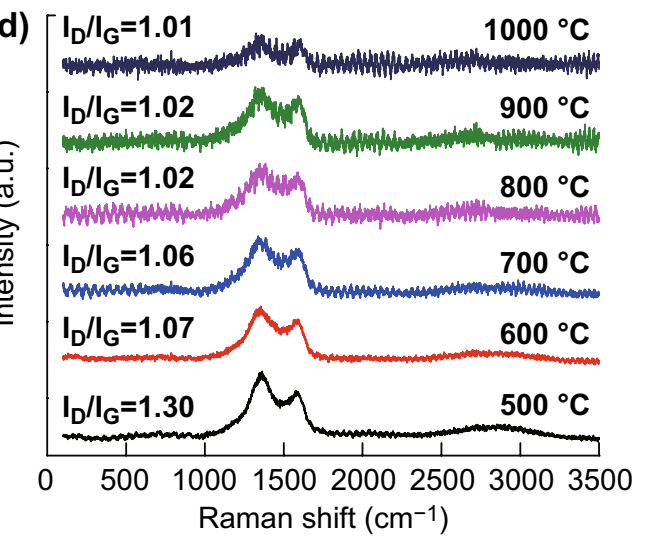

Fig. 3 a TG and DTG curves of Zn/Co-ZIFs/PAN nanofibers. b FT-IR spectra, c XRD patterns, and d Raman spectra of Zn/Co-ZIFs/PAN nanofibers and their carbonized samples with different carbonization temperatures $\left(500,600,700,800,900\right.$, and $\left.1000^{\circ} \mathrm{C}\right)$ 

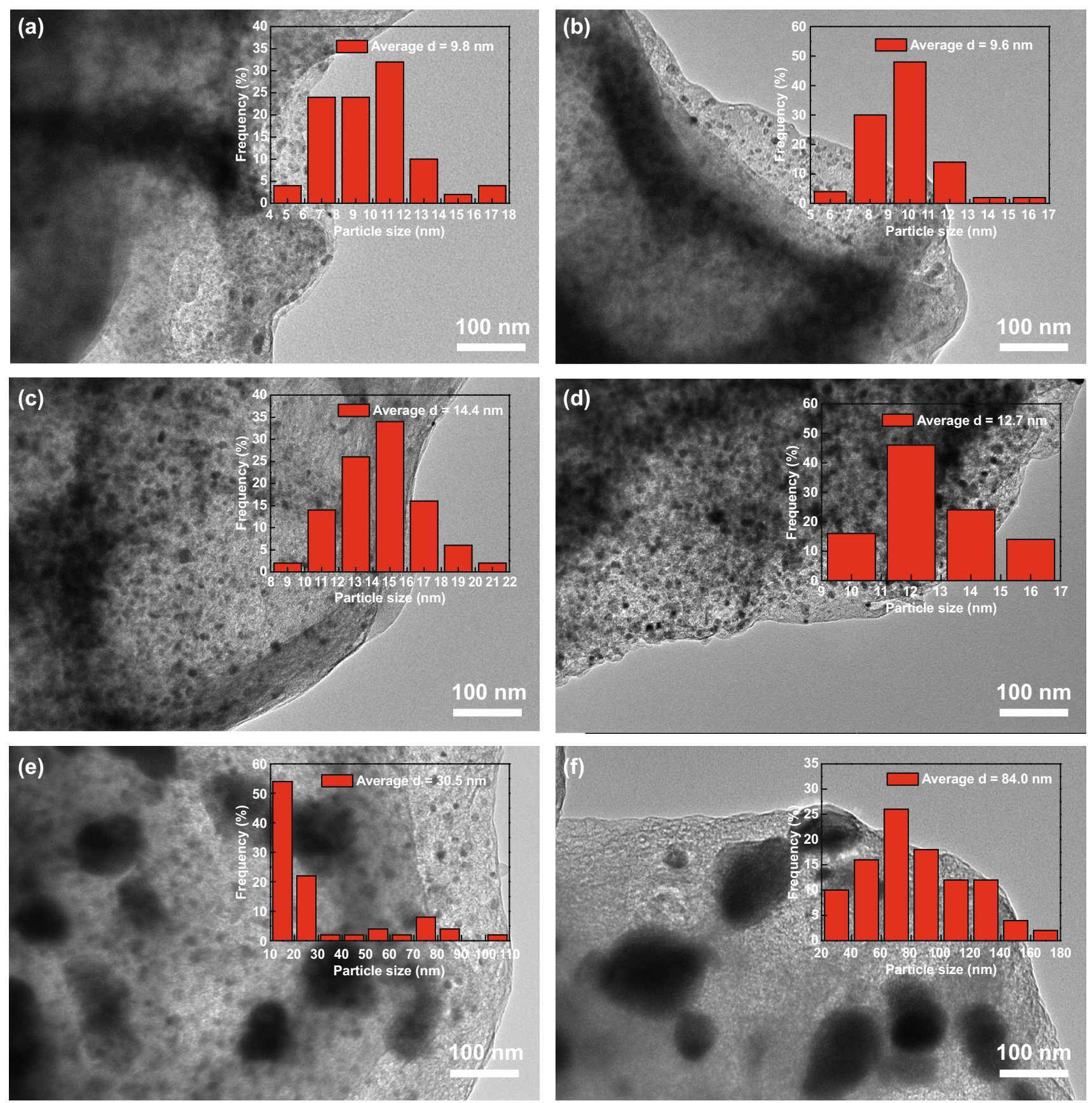

Fig. 4 TEM images of the samples obtained at different carbonization temperature: a $500{ }^{\circ} \mathrm{C}, \mathbf{b} 600{ }^{\circ} \mathrm{C}$, c $700{ }^{\circ} \mathrm{C}, \mathbf{d} 800{ }^{\circ} \mathrm{C}$, e $900{ }^{\circ} \mathrm{C}$, and f $1000^{\circ} \mathrm{C}$ (Insets are the size distributions of metal nanoparticles)

temperature from 500 to $1000{ }^{\circ} \mathrm{C}$, suggesting that $\mathrm{N}$ doping generates a defective extrinsic structure on the carbon framework of carbon nanofibers. The defective structures can increase active sites and, thus, enhance electrochemical performance [43]. Furthermore, the decrease in $I_{\mathrm{D}} / I_{\mathrm{G}}$ indicates the increase of the degree of graphitic crystalline structure at higher carbonization temperatures. A balance is reached between doping and graphitization during carbonization.

TEM images of different samples were taken to further characterize the detail change in metal nanoparticles during the carbonization process (Figs. 4, S4). These TEM images and the size distribution of metal nanoparticles clearly show 

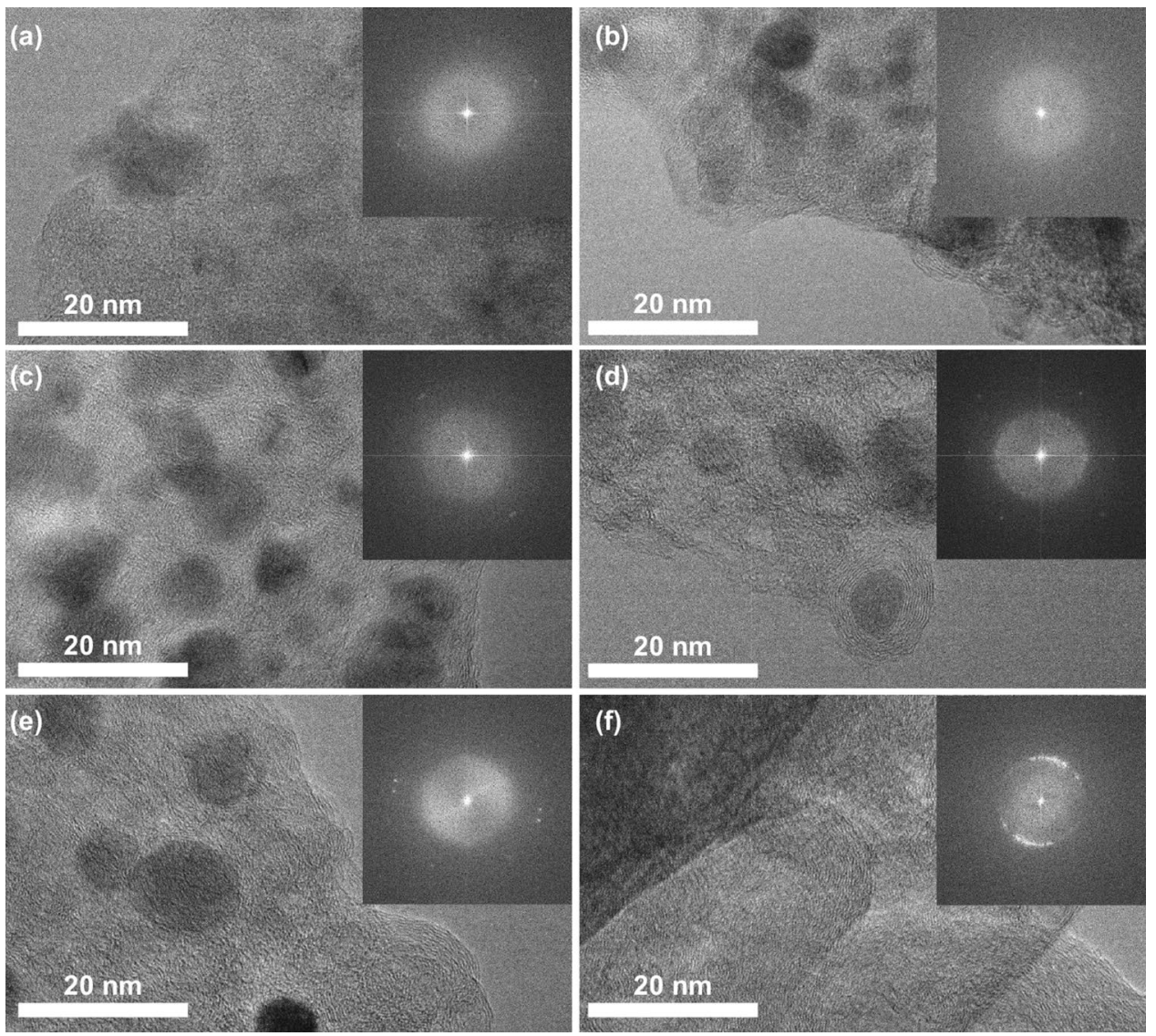

Fig. 5 High-magnification HR-TEM images of the samples at different carbonization temperature: a $500{ }^{\circ} \mathrm{C}, \mathbf{b} 600{ }^{\circ} \mathrm{C}, \mathbf{c} 700{ }^{\circ} \mathrm{C}, \mathbf{d} 800{ }^{\circ} \mathrm{C}$, e $900{ }^{\circ} \mathrm{C}$, and $\mathbf{f} 1000{ }^{\circ} \mathrm{C}$ (Insets are their corresponding SAED patterns)

that the metal nanoparticles became larger in size with increase of carbonization temperature. Serious agglomeration of metal nanoparticles occurred when the carbonization temperature was 900 and $1000{ }^{\circ} \mathrm{C}$, which does not assist the improvement of electrochemical performance because of the reduced surface area of active sites. Good distribution of doped-metal nanoparticles is important for excellent catalytic performance. As it can be seen from the results (Figs. 4, S4), the doped-metal nanoparticles were evenly distributed at carbonization temperatures of 700 and $800{ }^{\circ} \mathrm{C}$.

Furthermore, changes in carbon graphite structure and metal crystallization were observed by high magnification HR-TEM images and the SAED patterns (shown in Fig. 5). The degree of carbon graphitization increased significantly with increase of carbonization temperature, and the crystal diffraction spots show the improvement in metal crystallization. This result is consistent with the Raman and XRD results. The graphitized network structure is helpful for improving the electron transfer rate in the process of catalysis. As it can be seen from Fig. 5, the metal nanoparticles were embedded in the graphitic carbon layer, which makes them difficult to detach from the substrate during the electrocatalytic process.

Doping is an important factor affecting electrochemical properties. XPS analyses were carried out to further characterize the change in elemental composition and chemical status of these carbonized samples. As shown in Fig. S5a, $\mathrm{b}$, the elemental content of $\mathrm{Zn}, \mathrm{Co}$, and $\mathrm{N}$ decreased with increase of carbonization temperature, ranging from 500 to $1000{ }^{\circ} \mathrm{C}$. The $\mathrm{C} / \mathrm{O}$ ratio also increases with carbonization temperature, indicating that the conductivity gradually improved. The XPS and EDS results are consistent, which indicates that the composition of the material is uniform. The XPS high-resolution spectra of elemental $\mathrm{Zn}$ gradually disappeared when the temperature was above $900{ }^{\circ} \mathrm{C}$, as elemental Zn in ZIFs easily evaporates $\left(\sim 900^{\circ} \mathrm{C}\right)$, resulting 
in porous carbon structures during high-temperature treatment. The elemental content of cobalt increased first and then decreased with increase of carbonization temperature. This is due to the gradual doping of cobalt from the inside to the surface of nanofibers, which then evaporated at higher temperatures. The change in the content of elemental cobalt is consistent with the change in the nitrogen content, which imply the existence of $\mathrm{Co}-\mathrm{N}_{x}-\mathrm{C}$ species. At the temperature of $800{ }^{\circ} \mathrm{C}$, the sample has a relatively high content of cobalt and nitrogen. $\mathrm{N}$ atoms could incorporate into the graphene layers to replace carbon atoms at different sites during the carbonization process (above $700{ }^{\circ} \mathrm{C}$ ), and in doing so, they were split into various binding energies in the XPS spectra: pyridinic-N $398.7 \pm 0.3 \mathrm{eV}$, pyrrolic-N $400.4 \pm 0.3 \mathrm{eV}$, and graphitic-N $401.4 \pm 0.3 \mathrm{eV}$. It is worthy to note that carbons with pyridinic-N and pyrrolic-N at the edges of the graphene layers show higher charge mobility and better donor-acceptor properties than carbons with graphitic-N do [44].

As shown in Fig. 6c, pyridinic-N and pyrrolic-N gradually converted into graphitic- $\mathrm{N}$ with carbonization temperature. There was also a partial transformation between pyridinic$\mathrm{N}$ and pyrrolic- $\mathrm{N}$ in this process. Below the temperature of $700{ }^{\circ} \mathrm{C}$, some pyrrolic-N was converted into pyridinic- $\mathrm{N}$. Above the temperature of $700{ }^{\circ} \mathrm{C}$, the content of pyridinic- $\mathrm{N}$ was gradually reduced. The content of pyrrolic- $\mathrm{N}$ increased from 700 to $800{ }^{\circ} \mathrm{C}$ and then gradually decreased above $800{ }^{\circ} \mathrm{C}$. The total content of pyridinic-N and pyrrolic-N gradually decreased with the increase of temperature. At the temperatures of 700 and $800{ }^{\circ} \mathrm{C}$, there was a relatively higher amount of pyridinic-N and pyrrolic-N. The binding energy of nitrogen increased with temperature, which proves the existence of $\mathrm{Co}-\mathrm{N}_{x}-\mathrm{C}$. The high-resolution Co $2 \mathrm{p}$ spectra of the samples are shown in Fig. 6b. It can be deconvoluted into five major peaks, at 778.8, 780.4, 782.2, 795.4, and $797.0 \mathrm{eV}$, corresponding to $\mathrm{Co}^{0}, \mathrm{Co}^{3+} 2 p_{3 / 2}, \mathrm{Co}^{2+} 2 p_{3 / 2}, \mathrm{Co}^{3+}$ $2 p_{1 / 2}$, and $\mathrm{Co}^{2+} 2 p_{1 / 2}$, respectively, and two shakeup satellite peaks at 785.9 and $802.4 \mathrm{eV}[45,46]$. These peaks in the Co $2 p_{3 / 2}$ XPS spectra also imply the existence of Co- $\mathrm{N}_{x}-\mathrm{C}$ species [47]. In addition, the peak of the metallic $\mathrm{Co}$, located at the binding energy of $778.8 \mathrm{eV}$, confirms the presence of metallic cobalt nanoparticles [48]. This result is consistent with XRD and TEM results (Fig. 3c). The uniform dispersion of cobalt nanoparticles and the $\mathrm{Co}-\mathrm{N}_{x}-\mathrm{C}$ activity sites guarantee the high electrocatalyst performance.

Specific surface area is another important parameter that affects electrochemical performance. Large specific surface area may provide more active sites, especially for mesoporous structures. Macroporous structure also improves the mass transfer rate of electrolyte. The $\mathrm{N}_{2}$ adsorption-desorption isotherm and the corresponding pore-size distribution curves of the samples at different carbonization temperatures are shown in Figs. 7 and S6, respectively. The $\mathrm{N}_{2}$ adsorption-desorption isotherms demonstrate that the surface area increased with the increase of carbonization temperature. Above $700{ }^{\circ} \mathrm{C}$, the $\mathrm{N}_{2}$ adsorption-desorption isotherm becomes a type IV isotherm with an H3-type hysteresis loop $\left(P / P_{0}>0.4\right)$, suggesting the mesoporous characteristic of the Zn/Co-N@PCNFs. The BET specific surface areas are 7.6, 25.5, 199.9, 265.2, 309.3, and $366.4 \mathrm{~m}^{2} \mathrm{~g}^{-1}$, at carbonization temperatures of 500, 600, 700, 800, 900, and $1000{ }^{\circ} \mathrm{C}$, respectively. The pore-size distribution was calculated by the BJH method (shown in Fig. S6), and the average pore diameter of $\mathrm{Zn} / \mathrm{Co}-\mathrm{N} @ \mathrm{PCNF}$ decreased gradually. Above $700{ }^{\circ} \mathrm{C}$, many micropores appeared because of the volatilization of elemental zinc. At the same time, the average pore diameter is mesoporous below $5 \mathrm{~nm}$. The features of high surface area and pore structure can be well maintained after the high-temperature treatment, which is the key for enhancing the transport of oxygen and electrolyte onto the catalyst surface for ORR. Although samples carbonized at 900 and $1000{ }^{\circ} \mathrm{C}$ have the highest specific surface area, the agglomeration of the nanoparticles and the reduction in the doping element led to less active sites.

The electrocatalytic activity of the Zn/Co-N@PCNFs800 was first examined by $\mathrm{CV}$ measurements in $0.1 \mathrm{M} \mathrm{KOH}$ solution. As shown in Fig. 8a, no obvious redox peak is observed for Zn/Co-N @PCNFs-800 in 0.1 $\mathrm{M} \mathrm{N}_{2}$-saturated $\mathrm{KOH}$ solution. In contrast, a pronounced cathodic peak is clearly observed at $0.87 \mathrm{~V}$ (vs. RHE) in $0.1 \mathrm{M} \mathrm{O}_{2}$-saturated $\mathrm{KOH}$ solution. These results show the significant catalytic activity of oxygen reduction. The linear scan voltammetry (LSV) curves collected by the RDE demonstrate that $\mathrm{Zn} /$ Co-N@PCNFs-800 exhibited a better ORR activity (onset potential of $0.98 \mathrm{~V}$ vs. RHE), and half-wave potential (0.89 V vs. RHE). Zn/Co-N@PCNFs-800 also has larger diffusion-limited currents than the $20 \mathrm{wt} \% \mathrm{Pt} / \mathrm{C}$ has. For the other samples, the electrochemical performance first increased and then decreased with increase of carbonization temperature (Fig. S7). The excellent catalytic activity of Zn/ Co-N@PCNFs-800 may result from the synergistic effect of a small amount of zinc-doping $\mathrm{Co}-\mathrm{N}_{x}-\mathrm{C}$ species, uniform dispersion of Co nanoparticles and $\mathrm{N}$ dopants, high surface 

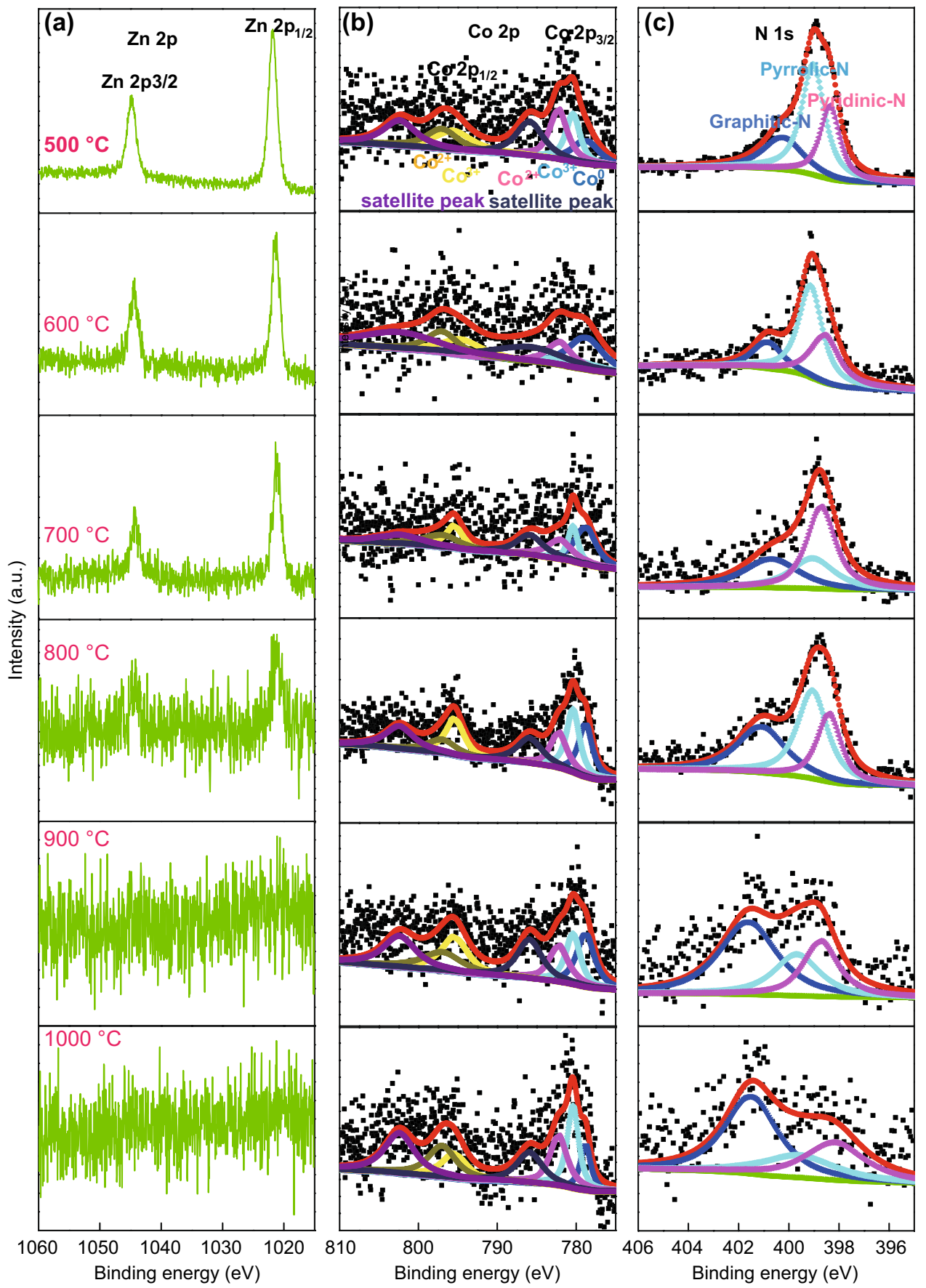

Fig. 6 XPS high-resolution spectra of a Zn $2 p$, b Co $2 p$, and $\mathbf{c} \mathrm{N} 1 s$ levels at different carbonization temperatures

area, distinct conductive carbon nanofibers, and hierarchical pore structure $[49,50]$. RDE measurements were conducted at various rotating speeds to investigate the kinetic parameters of Zn/Co-N@PCNFs-800 (Fig. 8c). With the increase in rotational speed, the diffusion current increased uniformly, which proves that the ORR process is well controlled by oxygen diffusion. The Koutecky-Levich (K-L) equation was used to analyze the kinetic parameters. The good linearity of the corresponding $\mathrm{K}-\mathrm{L}$ plots suggested the first-order reaction kinetics toward the concentration of dissolved oxygen 

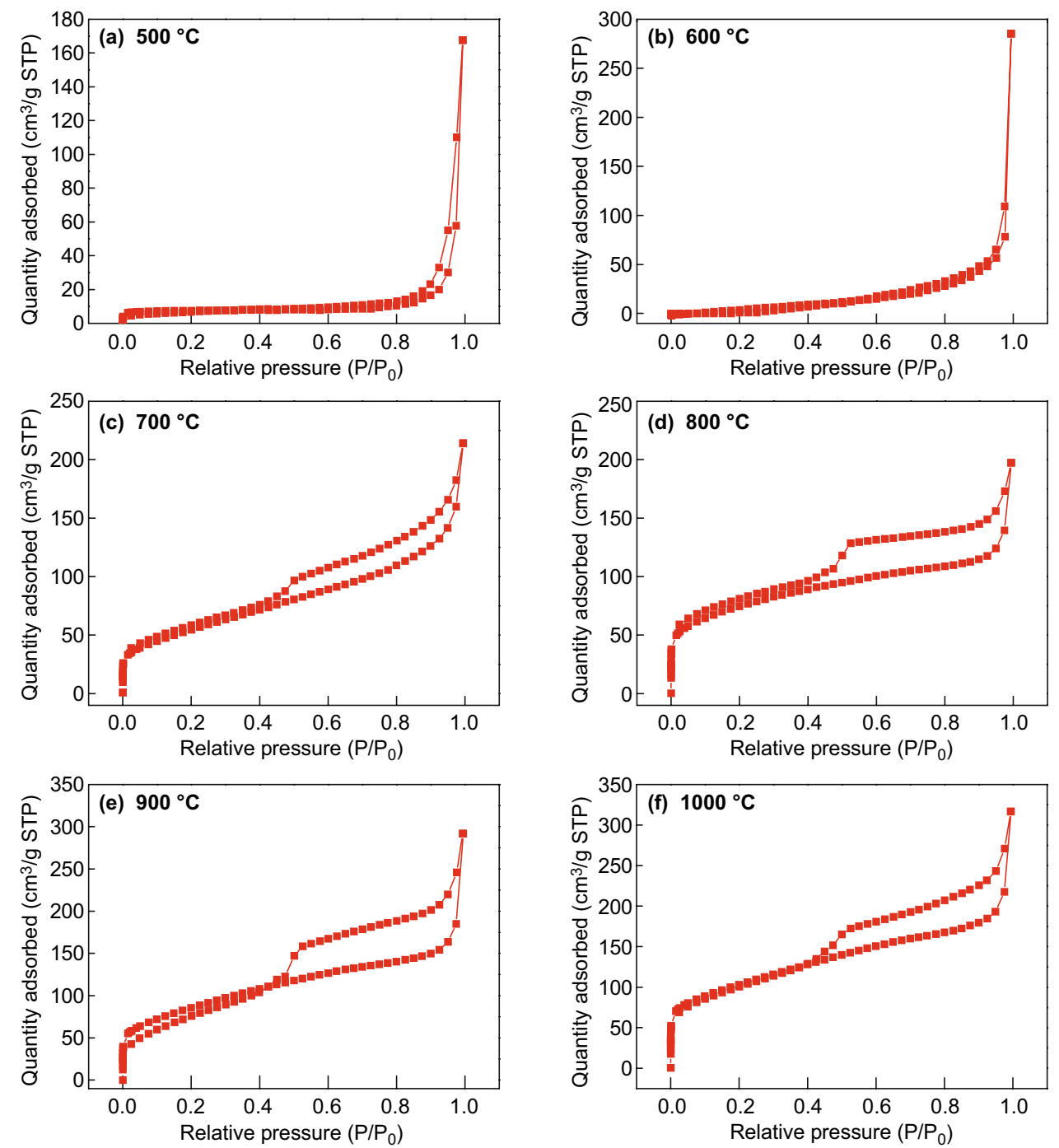

Fig. $7 \mathrm{~N}_{2}$ adsorption-desorption isotherm of the samples at different carbonization temperature: a $500{ }^{\circ} \mathrm{C}, \mathbf{b} 600{ }^{\circ} \mathrm{C}, \mathbf{c} 700{ }^{\circ} \mathrm{C}, \mathbf{d} 800{ }^{\circ} \mathrm{C}$, e $900{ }^{\circ} \mathrm{C}$, and f $1000{ }^{\circ} \mathrm{C}$

and at various potentials from 0.71 to $0.41 \mathrm{~V}$ (Fig. 8d). The electron transfer numbers at various potentials were calculated based on the K-L equations, and the obtained electron transfer number is about 3.88 from 0.71 to $0.41 \mathrm{~V}$ (V vs. RHE), indicating a direct four-electron oxygen reduction process (Fig. S8). Apart from the excellent ORR activity, Zn/Co-N@PCNFs-800 also exhibited much better stability and methanol tolerance as compared with the $20 \mathrm{wt} \%$ $\mathrm{Pt} / \mathrm{C}$. Chronoamperometric measurement at a voltage of $0.71 \mathrm{~V}$ recorded a greater than $94.53 \%$ current retention for a continuous 36,000 s operation (Fig. 8e). For comparison, $20 \mathrm{wt} \% \mathrm{Pt} / \mathrm{C}$ showed an significant activity decay with a less than $81.17 \%$ retention under the same testing conditions. In addition, Zn/Co-N@PCNFs-800 exhibited excellent resistance against methanol crossover. As shown in Fig. 8f, after the injection of $1 \mathrm{~mL}$ methanol, a slight change in the current occurred for our catalyst, while the cathodic current of $20 \mathrm{wt} \% \mathrm{Pt} / \mathrm{C}$ decreased sharply. To further test its electrochemical performance, the OER performance of $\mathrm{Zn} / \mathrm{Co}-\mathrm{N} @$ PCNFs-800 was tested (Fig. S9) in 0.1 M KOH solution. The Zn/Co-N@PCNFs-800 exhibited similar OER activity and more stable cyclic voltammetry, compared with the commercial $\mathrm{RuO}_{2}$ catalyst.

A homemade $\mathrm{Zn}$-air battery was further assembled to demonstrate the cell performance. The catalysts covering the PTFE-treated carbon fiber paper, $6 \mathrm{M} \mathrm{KOH}$, and a zinc 

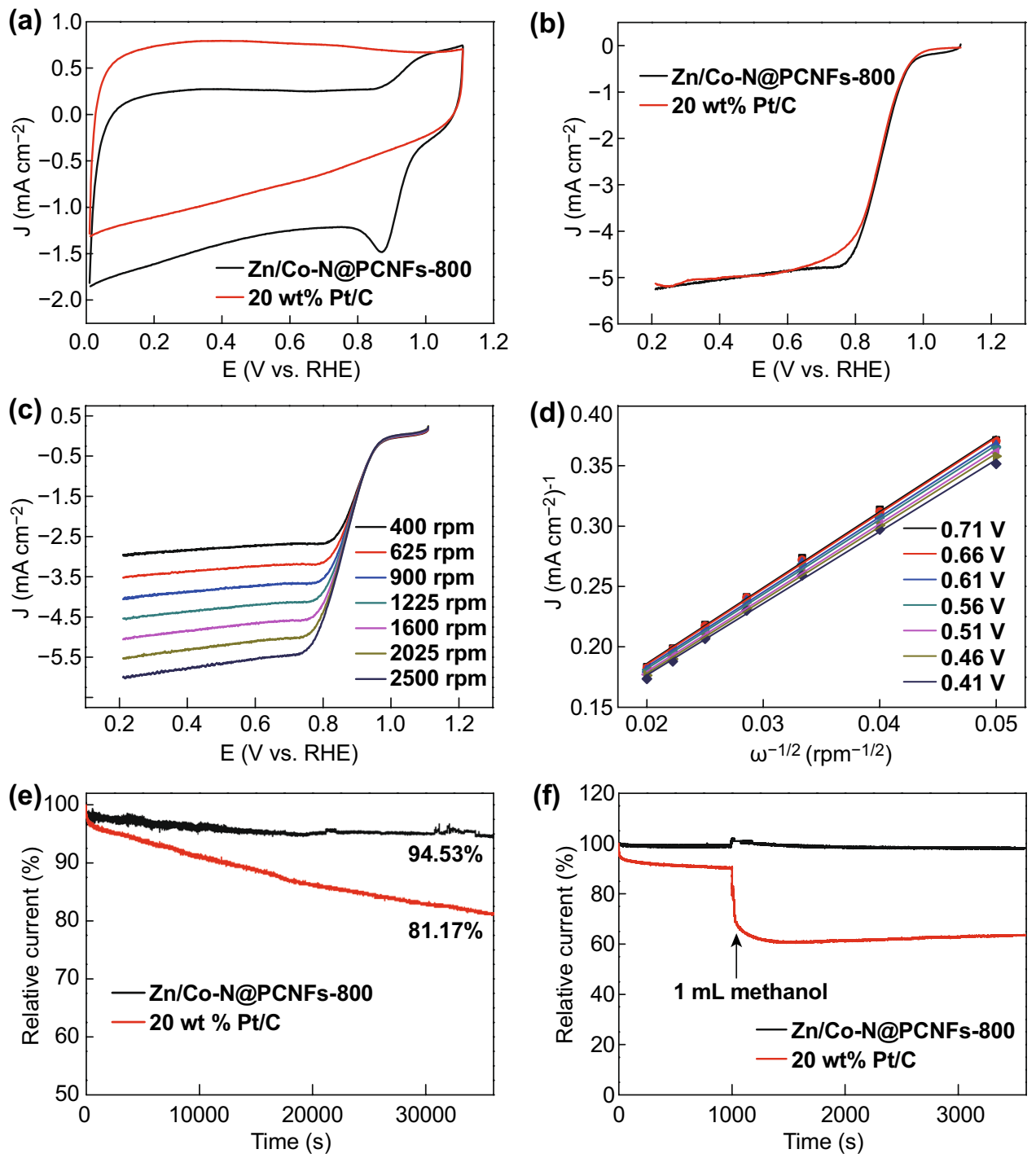

Fig. 8 a CV curves of $\mathrm{Zn} / \mathrm{Co}-\mathrm{N} @ \mathrm{PCNFs}-800$ in $0.1 \mathrm{M} \mathrm{N}_{2}$-saturated and $\mathrm{O}_{2}$-saturated $\mathrm{KOH}$ with a sweep rate of $50 \mathrm{mV} \mathrm{s}$. b LSV curves for $\mathrm{Zn} / \mathrm{Co}-\mathrm{N} @ \mathrm{PCNFs}-800$ and $20 \mathrm{wt} \% \mathrm{Pt} / \mathrm{C}$ in $0.1-\mathrm{M} \mathrm{O}_{2}$-saturated $\mathrm{KOH}$ electrolyte with a $10 \mathrm{mV} \mathrm{s}{ }^{-1}$ and a rotation rate of $1600 \mathrm{rpm}$. $\mathrm{c}$ LSV curves of Zn/Co-N@PCNFs-800 at different rotation speeds from 400 to 2500 rpm. d $K-L$ plots of Zn/Co-N@PCNFs- 800 at different potentials. e Chronoamperometric response of $\mathrm{Zn} / \mathrm{Co}-\mathrm{N} @ \mathrm{PCNFs}-800$ and $20 \mathrm{wt} \% \mathrm{Pt} / \mathrm{C}$ in $0.1 \mathrm{M} \mathrm{O}_{2}$-saturated $\mathrm{KOH}$ aqueous solution at $0.71 \mathrm{~V}$ versus RHE. f The durability test of Zn/Co-N@PCNFs-800 and 20 wt\% Pt/C for methanol. The arrow indicates the introduction of $1 \mathrm{~mL}$ methanol

foil acted as the air cathode, electrolyte, and anode, respectively (Fig. 9a). Figure 9b shows the catalytic mechanism diagram of cathode about Zn/Co-N@PCNFs-800. The carbon nanofiber matrix provides a good electron conduction transfer channel, the porous structure provides a mass transfer channel, and the uniform dispersion of metal nanoparticles provides sufficient activity sites. Two zinc-air batteries based on Zn/Co-N@PCNFs-800 catalysts were integrated in series to power a green light-emitting diode (LED, 1.8 V). An open-circuit voltage of ca. $1.425 \mathrm{~V}$ was observed when the battery was loaded with $\mathrm{Zn} / \mathrm{Co}-\mathrm{N} @$ PCNFs-800 in Fig. 9c. Figure 9d presents polarization and power density curves. Notably, the voltage decreases with the increase of current density, with the peak power density of Zn/Co-N@PCNFs-800 at $83.5 \mathrm{~mW} \mathrm{~cm}^{-2}$ for a current density of $124.5 \mathrm{~mA} \mathrm{~cm}^{-2}$, higher than that of $20 \mathrm{wt} \% \mathrm{Pt} / \mathrm{C}+\mathrm{RuO}_{2}\left(44.9 \mathrm{~mW} \mathrm{~cm}^{-2}\right.$ for a current density of $84.2 \mathrm{~mA} \mathrm{~cm}^{-2}$ ), further highlighting the key role of interconnected hierarchical porous structures in the fast electron/ion pathway and gas diffusion [51, 52]. 

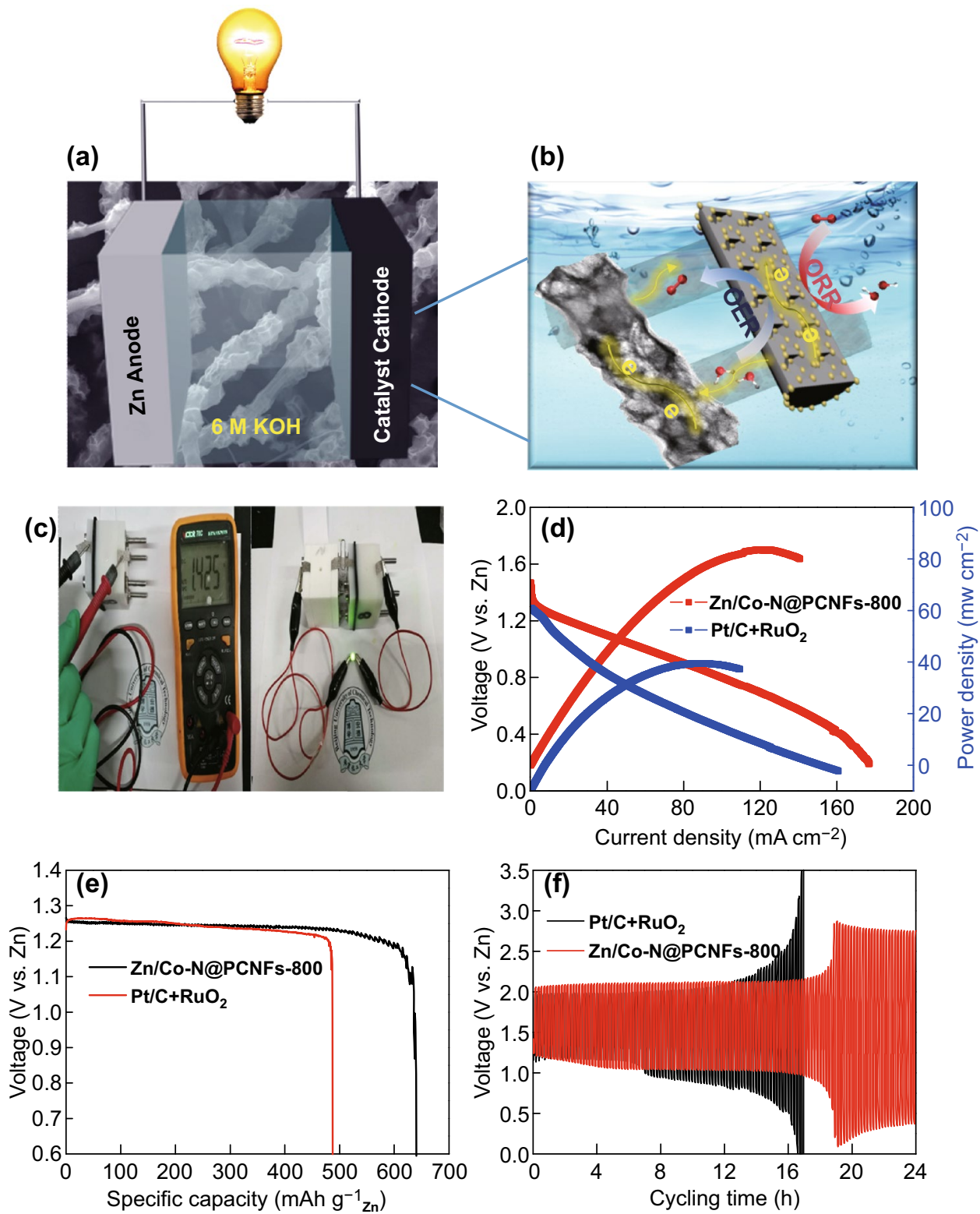

Fig. 9 a Schematic representation of the basic configuration of a two electrode $\mathrm{Zn}$-air battery by coupling the $\mathrm{Zn}$ electrode with an air electrode to execute ORR and OER in $6 \mathrm{M} \mathrm{KOH}$ solution as the electrolyte. b Catalytic mechanism diagram of cathode about Zn/Co-N@PCNFs-800. c Photographs of a green LED $(1.8 \mathrm{~V})$ powered by two $\mathrm{Zn}$-air batteries integrated in series. $\mathbf{d}$ Discharge polarization and power density curves of the $\mathrm{Zn}$-air batteries using $\mathrm{Zn} / \mathrm{Co}-\mathrm{N} @ \mathrm{PCNFs}-800$ and $20 \mathrm{wt} \% \mathrm{Pt} / \mathrm{C}+\mathrm{RuO}_{2}$ as ORR catalysts (mass loading of $1.2 \mathrm{mg} \mathrm{cm}^{-2}$ ). e Specific capacities for the $\mathrm{Zn}$-air battery using $\mathrm{Zn} / \mathrm{Co}-\mathrm{N} @ \mathrm{PCNFs}-800$ and $20 \mathrm{wt} \% \mathrm{Pt} / \mathrm{C}+\mathrm{RuO}_{2}$ as an ORR catalyst, which was regularized with consumed $\mathrm{Zn}$ mass. f Galvanostatic discharge and charge cycling curves at $10 \mathrm{~mA} \mathrm{~cm}{ }^{-2}$ with each cycle for 10 min $(5$ min charge and 5 min discharge) of rechargeable $\mathrm{Zn}$-air batteries with the $\mathrm{Zn} / \mathrm{Co}-\mathrm{N} @ \mathrm{PCNFs}-800$ and $20 \mathrm{wt} \% \mathrm{Pt} / \mathrm{C}+\mathrm{RuO}_{2}$ as the cathode catalyst

Zn/Co-N@PCNFs-800-based Zn-air batteries possess a specific capacity of $640.3 \mathrm{mAh} \mathrm{g}^{-1} \mathrm{Zn}$ when normalized to the mass of consumed $\mathrm{Zn}$ at a discharge density of $10 \mathrm{~mA} \mathrm{~cm}^{-2}$ (Fig. 9e). Figure 9f shows the galvanostatic discharge and charge cycling curves of rechargeable
$\mathrm{Zn}$-air batteries at $10 \mathrm{~mA} \mathrm{~cm}{ }^{-2}$ with $10 \mathrm{~min}$ cycles $(5 \mathrm{~min}$ charge and 5 min discharge), with the Zn/Co-N@PCNFs800 and $20 \mathrm{wt} \% \mathrm{Pt} / \mathrm{C}+\mathrm{RuO}_{2}$ as the cathode catalyst. $\mathrm{Zn} /$ Co-N@PCNFs-800 exhibited excellent reversibility and 
better cycling life (more than $18 \mathrm{~h}$ ) than the commercial $20 \mathrm{wt} \% \mathrm{Pt} / \mathrm{C}+\mathrm{RuO}_{2}(\sim 16 \mathrm{~h})$ catalysts.

\section{Conclusions}

In summary, flexible, porous, and well-dispersed metal-heteroatom-doped carbon nanofibers were prepared by a direct high-temperature carbonization approach using electrospun $\mathrm{Zn} / \mathrm{Co}$-ZIFs/PAN nanofibers as the precursor. The flexible porous bimetal-heteroatom-doped carbon nanofibers exhibited the excellent ORR electrocatalytic activity, superior stability, and methanol tolerance under $0.1 \mathrm{M} \mathrm{KOH}$ solution, which can be ascribed to the synergistic effect of $\mathrm{Co}-\mathrm{N}_{x}$ species, uniform dispersions of Co nanoparticles and $\mathrm{N}$ dopants, high surface area, distinct conductive curving of carbon nanofibers, as well as the hierarchical pore structure. The excellent ORR performance was also demonstrated in a homemade rechargeable zinc-air battery. In addition, this Zn/Co-N@PCNFs-800 film exhibited good flexibility, which could be applied to flexible devices. Our work illustrates the great potentials of hybrid porous carbon nanofiber materials as ORR and OER electrocatalysts. We hope that this work can spark interests in developing multi-functional electrocatalysts toward application in renewable energy technologies.

Acknowledgements The authors would like to thank the Natural Science Foundation of Jiangsu Province (Grant No. BK20171200) for their financial support. The authors also wish to acknowledge the support provided by the Excellent PhD International Visit Program of Beijing University of Chemical Technology. The authors also wish to acknowledge the $\mathrm{Zn}$-air battery tests by Jinhe Shu from Beijing University of Chemical Technology. We are also sincerely grateful to my friends (Yige Zhao; Nannan Guo; Yongzheng Shi; they are all from Beijing University of Chemical Technology) for the advices and help to my experiments.

Open Access This article is distributed under the terms of the Creative Commons Attribution 4.0 International License (http:// creativecommons.org/licenses/by/4.0/), which permits unrestricted use, distribution, and reproduction in any medium, provided you give appropriate credit to the original author(s) and the source, provide a link to the Creative Commons license, and indicate if changes were made.

Electronic supplementary material The online version of this article (doi:https://doi.org/10.1007/s40820-019-0238-4) contains supplementary material, which is available to authorized users.

\section{References}

1. S. Chu, A. Majumdar, Opportunities and challenges for a sustainable energy future. Nature 488(7411), 294-303 (2012). https://doi.org/10.1038/nature11475

2. L. Dai, Y. Xue, L. Qu, H.J. Choi, J.B. Baek, Metal-free catalysts for oxygen reduction reaction. Chem. Rev. 115(11), 4823-4892 (2015). https://doi.org/10.1021/cr5003563

3. Z. Chen, D. Higgins, A. Yu, L. Zhang, J. Zhang, A review on non-precious metal electrocatalysts for pem fuel cells. Energy Environ. Sci. 4(9), 3167 (2011). https://doi. org/10.1039/c0ee00558d

4. M. Shao, Q. Chang, J.P. Dodelet, R. Chenitz, Recent advances in electrocatalysts for oxygen reduction reaction. Chem. Rev. 116(6), 3594-3657 (2016). https://doi. org/10.1021/acs.chemrev.5b00462

5. Y.Z. Chen, C. Wang, Z.Y. Wu, Y. Xiong, Q. Xu, S.H. Yu, H.L. Jiang, From bimetallic metal-organic framework to porous carbon: high surface area and multicomponent active dopants for excellent electrocatalysis. Adv. Mater. 27(34), 5010-5016 (2015). https://doi.org/10.1002/adma.201502315

6. Q.L. Zhu, W. Xia, T. Akita, R. Zou, Q. Xu, Metal-organic framework-derived honeycomb-like open porous nanostructures as precious-metal-free catalysts for highly efficient oxygen electroreduction. Adv. Mater. 28(30), 6391-6398 (2016). https://doi.org/10.1002/adma.201600979

7. J. Zhu, H. Zhou, C. Zhang, J. Zhang, S. Mu, Dual active nitrogen doped hierarchical porous hollow carbon nanospheres as an oxygen reduction electrocatalyst for zinc-air batteries. Nanoscale 9(35), 13257-13263 (2017). https://doi. org/10.1039/C7NR04349J

8. P. Huang, H. Li, X. Huang, D. Chen, Multiheteroatom-doped porous carbon catalyst for oxygen reduction reaction prepared using 3D network of ZIF-8/polymeric nanofiber as a facile-doping template. ACS Appl. Mater. Interfaces 9(25), 21083-21088 (2017). https://doi.org/10.1021/acsami.7b064 27

9. Q. Liu, Y. Wang, L. Dai, J. Yao, Scalable fabrication of nanoporous carbon fiber films as bifunctional catalytic electrodes for flexible Zn-air batteries. Adv. Mater. 28(15), 3000-3006 (2016). https://doi.org/10.1002/adma.201506112

10. G. Ren, X. Lu, Y. Li, Y. Zhu, L. Dai, L. Jiang, Porous coreshell $\mathrm{Fe}_{3} \mathrm{C}$ embedded $\mathrm{N}$-doped carbon nanofibers as an effective electrocatalysts for oxygen reduction reaction. ACS Appl. Mater. Interfaces 8(6), 4118-4125 (2016). https://doi. org/10.1021/acsami.5b11786

11. Z. Li, M. Shao, L. Zhou, R. Zhang, C. Zhang, M. Wei, D.G. Evans, X. Duan, Directed growth of metal-organic frameworks and their derived carbon-based network for efficient electrocatalytic oxygen reduction. Adv. Mater. 28(12), 2337-2344 (2016). https://doi.org/10.1002/adma.201505086

12. J. Wei, Y. Hu, Z. Wu, Y. Liang, S. Leong et al., A graphenedirected assembly route to hierarchically porous $\mathrm{Co}-\mathrm{N}_{\mathrm{x}} / \mathrm{C}$ catalysts for high-performance oxygen reduction. J. Mater. Chem. A 3, 16867-16873 (2015). https://doi.org/10.1039/ C5TA04330A 
13. Q. Niu, J. Guo, Y. Tang, X. Guo, J. Nie, G. Ma, Sandwich-type bimetal-organic frameworks/graphene oxide derived porous nanosheets doped Fe/Co-n active sites for oxygen reduction reaction. Electrochim. Acta 255, 72-82 (2017). https://doi. org/10.1016/j.electacta.2017.09.125

14. S. Hu, T. Han, C. Lin, W. Xiang, Y. Zhao, P. Gao, F. Du, X. $\mathrm{Li}$, Y. Sun, Enhanced electrocatalysis via 3D graphene aerogel engineered with a silver nanowire network for ultrahigh-rate zinc-air batteries. Adv. Funct. Mater. 27(18), 1700041 (2017). https://doi.org/10.1002/adfm.201700041

15. S.S. Shinde, C.H. Lee, J.Y. Yu, D.H. Kim, S.U. Lee, J.H. Lee, Hierarchically designed $3 \mathrm{~d}$ holey $\mathrm{C}_{2} \mathrm{~N}$ aerogels as bifunctional oxygen electrodes for flexible and rechargeable zn-air batteries. ACS Nano 12(1), 596-608 (2018). https:// doi.org/10.1021/acsnano.7b07473

16. S. Dang, Q.L. Zhu, Q. Xu, Nanomaterials derived from metal-organic frameworks. Nat. Rev. Mater. 3(1), 17075 (2017). https://doi.org/10.1038/natrevmats.2017.75

17. K. Shen, X. Chen, J. Chen, Y. Li, Development of mofderived carbon-based nanomaterials for efficient catalysis. ACS Catal. 6(9), 5887-5903 (2016). https://doi.org/10.1021/ acscatal.6b01222

18. B. Liu, H. Shioyama, T. Akita, Q. Xu, Metal-organic framework as a template for porous carbon synthesis. J. Am. Chem. Soc. 130, 5390-5391 (2008). https://doi.org/10.1021/ ja7106146

19. B. Chen, Z. Yang, Y. Zhu, Y. Xia, Zeolitic imidazolate framework materials: recent progress in synthesis and applications. J. Mater. Chem. A 2(40), 16811-16831 (2014). https://doi.org/10.1039/C4TA02984D

20. B. Chen, G. Ma, Y. Zhu, Y. Xia, Metal-organic-frameworks derived cobalt embedded in various carbon structures as bifunctional electrocatalysts for oxygen reduction and evolution reactions. Sci. Rep. 7(1), 5266 (2017). https://doi. org/10.1038/s41598-017-05636-y

21. W. Zhang, Z.Y. Wu, H.L. Jiang, S.H. Yu, Nanowire-directed templating synthesis of metal-organic framework nanofibers and their derived porous doped carbon nanofibers for enhanced electrocatalysis. J. Am. Chem. Soc. 136(41), 14385-14388 (2014). https://doi.org/10.1021/ja5084128

22. S.H. Ahn, M.J. Klein, A. Manthiram, 1D Co- and N-doped hierarchically porous carbon nanotubes derived from bimetallic metal organic framework for efficient oxygen and tri-iodide reduction reactions. Adv. Energy Mater. 7(7), 1601979 (2017). https://doi.org/10.1002/aenm.201601979

23. S.H. Ahn, X. Yu, A. Manthiram, "Wiring" Fe- $\mathrm{N}_{\mathrm{x}}$-embedded porous carbon framework onto 1D nanotubes for efficient oxygen reduction reaction in alkaline and acidic media. Adv. Mater. 29(26), 1606534 (2017). https://doi.org/10.1002/ adma.201606534

24. C. Zhang, Y.C. Wang, B. An, R. Huang, C. Wang, Z. Zhou, W. Lin, Networking pyrolyzed zeolitic imidazolate frameworks by carbon nanotubes improves conductivity and enhances oxygen-reduction performance in polymer-electrolyte-membrane fuel cells. Adv. Mater. 29(4), 1604556 (2017). https://doi.org/10.1002/adma.201604556
25. P.C. Shi, J.D. Yi, T.T. Liu, L. Li, L.J. Zhang et al., Hierarchically porous nitrogen-doped carbon nanotubes derived from core-shell ZnO@zeolitic imidazolate framework nanorods for highly efficient oxygen reduction reactions. J. Mater. Chem. A 5, 12322-12329 (2017). https://doi.org/10.1039/ C7TA02999C

26. C. Lin, S.S. Shinde, Z. Jiang, X. Song, Y. Sun, L. Guo, H. Zhang, J.Y. Jung, X. Li, J.H. Lee, In situ directional formation of Co@ $\mathrm{CoO}_{\mathrm{x}}$-embedded 1D carbon nanotubes as an efficient oxygen electrocatalyst for ultra-high rate zn-air batteries. J. Mater. Chem. A 5, 13994-14002 (2017). https://doi. org/10.1039/C7TA02215H

27. F. Meng, H. Zhong, D. Bao, J. Yan, X. Zhang, In situ coupling of strung Co4N and intertwined $\mathrm{N}-\mathrm{C}$ fibers toward freestanding bifunctional cathode for robust, efficient, and flexible Zn-air batteries. J. Am. Chem. Soc. 138(32), 10226-10231 (2016). https://doi.org/10.1021/jacs.6b05046

28. S.S. Shinde, J.Y. Yu, J.W. Song, Y.H. Nam, D.H. Kim, J.H. Lee, Highly active and durable carbon nitride fibers as metalfree bifunctional oxygen electrodes for flexible $\mathrm{Zn}$-air batteries. Nanoscale Horiz. 2(6), 333-341 (2017). https://doi. org/10.1039/C7NH00058H

29. X. Wang, J. Yu, G. Sun, B. Ding, Electrospun nanofibrous materials: a versatile medium for effective oil/water separation. Mater. Today 19(7), 403-414 (2016). https://doi. org/10.1016/j.mattod.2015.11.010

30. G. Yang, X. Li, Y. He, J. Ma, G. Ni, S. Zhou, From nano to micro to macro: electrospun hierarchically structured polymeric fibers for biomedical applications. Prog. Polym. Sci. 81, 80-113 (2018). https://doi.org/10.1016/j.progpolyms ci.2017.12.003

31. L. Li, S. Peng, J. Lee, D. Ji, M. Srinivasan, S. Ramakrishna, Electrospun hollow nanofibers for advanced secondary batteries. Nano Energy 39, 111-139 (2017). https://doi. org/10.1016/j.nanoen.2017.06.050

32. X. Lu, C. Wang, F. Favier, N. Pinna, Electrospun nanomaterials for supercapacitor electrodes: designed architectures and electrochemical performance. Adv. Energy Mater. 7(2), 1601301 (2017). https://doi.org/10.1002/aenm.201601301

33. Y. Zhao, J. Zhang, X. Guo, H. Fan, W. Wu, H. Liu, G. Wang, $\mathrm{Fe}_{3} \mathrm{C} @$ nitrogen doped cnt arrays aligned on nitrogen functionalized carbon nanofibers as highly efficient catalysts for the oxygen evolution reaction. J. Mater. Chem. A 5(37), 1967219679 (2017). https://doi.org/10.1039/C7TA05936A

34. Q. Niu, J. Guo, B. Chen, J. Nie, X. Guo, G. Ma, Bimetalorganic frameworks/polymer core-shell nanofibers derived heteroatom-doped carbon materials as electrocatalysts for oxygen reduction reaction. Carbon 114, 250-260 (2017). https ://doi.org/10.1016/j.carbon.2016.12.016

35. C. Liu, J. Wang, J. Li, J. Liu, C. Wang, X. Sun, J. Shen, W. Han, L. Wang, Electrospun ZIF-based hierarchical carbon fiber as an efficient electrocatalyst for the oxygen reduction reaction. J. Mater. Chem. A 5(3), 1211-1220 (2017). https:// doi.org/10.1039/C6TA09193H

36. R. Wu, K. Zhou, J. Wei, J. Lou, M. Pulickel, Porous spinel $\mathrm{Zn}_{\mathrm{x}} \mathrm{Co}_{3-\mathrm{x}} \mathrm{O}_{4}$ hollow polyhedra templated for high-rate 
lithium-ion batteries. ACS Nano 8(6), 6297-6303 (2014). https://doi.org/10.1021/nn501783n

37. C. Wang, H. Wang, R. Luo, C. Liu, J. Li, X. Sun, J. Shen, W. Han, L. Wang, Metal-organic framework one-dimensional fibers as efficient catalysts for activating peroxymonosulfate. Chem. Eng. J. 330, 262-271 (2017). https://doi.org/10.1016/j. cej.2017.07.156

38. Q. Guo, D. Zhao, S. Liu, S. Chen, M. Hanif, H. Hou, Freestanding nitrogen-doped carbon nanotubes at electrospun carbon nanofibers composite as an efficient electrocatalyst for oxygen reduction. Electrochim. Acta 138, 318-324 (2014). https://doi.org/10.1016/j.electacta.2014.06.120

39. Q. Wang, Y. Li, K. Wang, J. Zhou, L. Zhu, L. Gu, J. Hu, X. Cao, Mass production of porous biocarbon self-doped by phosphorus and nitrogen for cost-effective zinc-air batteries. Electrochim. Acta 257, 250-258 (2017). https://doi. org/10.1016/j.electacta.2017.10.055

40. L. Zhang, A. Aboagye, A. Kelkar, C. Lai, H. Fong, A review: carbon nanofibers from electrospun polyacrylonitrile and their applications. J. Mater. Sci. 49(2), 463-480 (2013). https://doi. org/10.1007/s10853-013-7705-y

41. X. Yan, L. Gan, Y.C. Lin, L. Bai, T. Wang, X. Wang, J. Luo, J. Zhu, Controllable synthesis and enhanced electrocatalysis of iron-based catalysts derived from electrospun nanofibers. Small 10(20), 4072-4079 (2014). https://doi.org/10.1002/ smll.201470122

42. B. Sun, Y.Z. Long, Z.J. Chen, S.L. Liu, H.D. Zhang, J.C. Zhang, W.P. Hana, Recent advances in flexible and stretchable electronic devices via electrospinning. J. Mater. Chem. C 2, 1209-1219 (2014). https://doi.org/10.1039/C3TC31680G

43. D. Yan, Y. Li, J. Huo, R. Chen, L. Dai, S. Wang, Defect chemistry of nonprecious-metal electrocatalysts for oxygen reactions. Adv. Mater. 29(48), 1606459 (2017). https://doi. org/10.1002/adma.201606459

44. D. Guo, R. Shibuya, C. Akiba, S. Saji, T. Kondo, J. Nakamura, Active sites of nitrogen-doped carbon materials for oxygen reduction reaction clarified using model catalysts. Science 351, 361-365 (2016). https://doi.org/10.1126/science.aad0832

45. H. Wang, F.X. Yin, B.H. Chen, X.B. He, P.L. Lv, C.Y. Ye, D.J. Liu, ZIF-67 incorporated with carbon derived from pomelo peels: a highly efficient bifunctional catalyst for oxygen reduction/evolution reactions. Appl. Catal. B: Environ. 205, 55-67 (2017). https://doi.org/10.1016/j.apcatb.2016.12.016

46. F. Yang, P. Zhao, X. Hua, W. Luo, G. Cheng, W. Xing, S. Chen, A cobalt-based hybrid electrocatalyst derived from a carbon nanotube inserted metal-organic framework for efficient water-splitting. J. Mater. Chem. A 4(41), 16057-16063 (2016). https://doi.org/10.1039/C6TA05829A

47. J. Yang, X. Wang, B. Li, L. Ma, L. Shi, Y. Xiong, H. Xu, Novel iron/cobalt-containing polypyrrole hydrogel-derived trifunctional electrocatalyst for self-powered overall water splitting. Adv. Funct. Mater. 27(17), 1606497 (2017). https:// doi.org/10.1002/adfm.201606497

48. H. Liu, X. Wang, H. Xu, W. Yu, X. Dong, Y. Yang, H. Zhang, J. Wang, Nanostructured coo/nio/coni anodes with tunable morphology for high performance lithium-ion batteries. Dalton Trans. 46(33), 11031-11036 (2017). https://doi. org/10.1039/C7DT01904A

49. C. Zhang, B. Lu, F. Cao, Z. Wu, W. Zhang, H. Cong, S. Yu, Electrospun metal-organic framework nanoparticle fibers and their derived electrocatalysts for oxygen reduction reaction. Nano Energy 55, 226-233 (2019). https://doi.org/10.1016/j. nanoen.2018.10.029

50. C. Li, M. Wu, R. Liu, High-performance bifunctional oxygen electrocatalysts for zinc-air batteries over mesoporous $\mathrm{Fe} / \mathrm{Co}-$ $\mathrm{N}-\mathrm{C}$ nanofibers with embedding FeCo alloy nanoparticles. Appl. Catal. B: Environ. 244, 150-158 (2019). https://doi. org/10.1016/j.apcatb.2018.11.039

51. H. Xia, J. Zhang, Z. Yang, S. Guo, S. Guo, Q. Xu, 2D MOF nanoflake-assembled spherical microstructures for enhanced supercapacitor and electrocatalysis performances. Nano-Micro Lett. 9, 43 (2017). https://doi.org/10.1007/s40820-017-0144-6

52. R. Xing, T. Zhou, Y. Zhou, R. Ma, Q. Liu, J. Luo, J. Wang, Creation of triple hierarchical micro-meso-macroporous $\mathrm{N}$-doped carbon shells with hollow cores toward the electrocatalytic oxygen reduction reaction. Nano-Micro Lett. 10, 3 (2018). https://doi.org/10.1007/s40820-017-0157-1 